\title{
Assessing the Awareness and Usage of Quality Control Tools with Emphasis to Statistical Process Control (SPC) in Ethiopian Manufacturing Industries
}

\author{
Leakemariam Berhe, Tesfay Gidey \\ Department of Statistics, Addis Ababa Science and Technology University, Addis Ababa, Ethiopia \\ Email: tesfay.gidey@aastu.edu.et
}

How to cite this paper: Berhe, L. and Gidey, T. (2016) Assessing the Awareness and Usage of Quality Control Tools with Emphasis to Statistical Process Control (SPC) in Ethiopian Manufacturing Industries. Intelligent Information Management, 8, 143169.

http://dx.doi.org/10.4236/iim.2016.86011

Received: July 28, 2016

Accepted: November 6, 2016

Published: November 9, 2016

Copyright $\odot 2016$ by authors and Scientific Research Publishing Inc. This work is licensed under the Creative Commons Attribution International License (CC BY 4.0).

http://creativecommons.org/licenses/by/4.0/

\begin{abstract}
Introduction: The present work was devoted to assess the awareness and usage of quality control tools with the emphasis on statistical process control in Ethiopian manufacturing industries. Semi structured questionnaire has been employed to executive and technical managers of manufacturing industries of various size and specialism across the country. Stratified random sample method by region was used to select sample industries for the study. The samples used for this study are industries mainly from Oromiya, Addis Ababa, Tigray, Amara, SNNP and Dire-dawa regions proportional to their size of the available industries. Methods: Exploratory method and descriptive statistics was used for data analysis. Available documents and reports related to quality control policy of the selected companies were investigated. Results and Discussions: The number of manufacturing industries involved in this study was 44 . Of the sampled manufacturing industries about $60 \%$ are from Oromiya and Addis Ababa regions. It has been reported that $100 \%$ of the respondents said that the importance of quality control tools is very important to their organizations' productivity and quality improvement (Figure 3). Quality control professionals were also asked the extent to which quality control system is working in their industry and majority of the respondents (45\%) have indicated that quality control system is working to some extent in their respective industries (Figure 18). Conclusions and Recommendations: Most of the quality department of the industries did not fully recognize the importance of statistical process control as quality control tools. This is mainly due to lack of awareness and motivation of the top managements, shortage of man power in the area, and others together would make it difficult to apply quality control tools in their organization. In general, the industries in Ethiopia are deficient in vigor and found to be stagnant hence less exposed to a highly competitive market
\end{abstract}


and don't adopt the latest quality control techniques in order to gain knowledge about systems to improve quality and operational performance. We conclude that quality management system has to be established as an independent entity with a real power and hence the quality control department which is responsible for quality can make an irreversible decision with respect to quality of any given product. Moreover, the concerned bodies (government and ministry of industries) should give attention and work together with universities to ensure how these statistical process control techniques could be incorporated in a curriculum of the universities at higher levels in degree and masters programs. Furthermore, different trainings which could improve quality and efficiency of their respective management system should be given as short and long term to the employees including top and middle managers found in various industries relevant to their process.

\section{Keywords}

Quality Products, Awareness, Usage, Statistical Process Control, Ethiopia

\section{Introduction}

\subsection{Quality Control}

As stated by Garvin in 1987 quality of a product is by and large considered as the aptitude of a stiff to endow with products that gratify the customer and the market [1]. The term quality is regularly characterized as multidimensional criterion: performance, features, reliability, conformance, durability, serviceability, aesthetics, and perceived quality. In this regard, quality is a multifaceted entity and hence, a simple definition to quality or quality improvement is not easy. The phrase "fitness for use" noted as customary concept of quality whereas the contemporary definition for quality depicted as "inversely proportional to variability" [2]. Accordingly, the quality of a product increases if variability in the important characteristics of a product decreases. One hence can understand that quality improvement is the reduction of variability in processes and products. Failure to control variations among products will lead to customer dissatisfaction or the products would not match customer expectations.

Now days the conception of controlling and improving quality of a product has become as crucial business approach in many institutions. This approach can delight customers and take over its competitors through improving and controlling quality [2]. In the manufacturing environment, quality improves reliability, increases productivity and customer satisfaction [3]. Quality improvement has become the key feature for the development of any business organization. The need for quality has long been recognized as very important to both competition and survival in the business world. It has been noted that falling behind the race for quality and efficiency means that it is being out of business. It has been witnessed that the economic developments in many industries during the end of $20^{\text {th }}$ century have come to be labeled agitated competition. Several industries including the automotive industry, the foods industry and consumer 
electronics have increasingly competed with each other on higher and higher levels of efficiency and quality [4]. In the late twenty century, the Japanese quality revolution brought the Western industries to a state of recession [4].

\subsection{Continuous Improvement}

Quality is not a one-time effort phenomenon. In order to survive and win global competition, continuous effort for quality improvement is necessary. In this contemporary world, there is an increasing speed and complication of business environments hence organizations should continuously improve their processes [5]. Continuous improvement (CI) can be considered the systematic effort to seek out and apply new ways of doing work. The term CI simply refers to making process improvements actively and repeatedly. The processes can be viewed as designed sequences of tasks aimed at creating value-adding transformations of inputs-material and information-to achieve intended outputs [6].

Continuous improvement (CI) is a philosophy that Deming described simply as consisting of "Improvement initiatives that increase successes and reduce failures" [7]. Bessant et al. (1994) defined CI is "a company-wide process of focused and continuous incremental innovation" [8]. Over the decades, as the need to continuously improve on a larger scale within the organization became an imperative, a number of CI methodologies have developed based on a basic concept of quality or process improvement, or both, in order to reduce waste, simplify the production line and improve quality. However, not all organizations that have deployed continuous improvement initiatives have been successful in getting what they set out to achieve [9]. Although operations management executives realize the importance of continually improving processes, they have found that managing continuous improvement is a challenging task [10]. The challenge lies in creating an infrastructure to coordinate continuous improvement projects [11].

The common CI methodologies are lean manufacturing, six sigma, the balanced scorecard, and lean six sigma [12]. For completeness, these four CI methodologies are briefly introduced. Taiichi Ohno, former executive vice president of Toyota, pioneered and developed the world renowned Toyota Production System (TPS), also known as lean manufacturing and now used throughout the world [13]. The methodology is designed to maintain a continuous flow of products in factories in order to flexibly adjust to changes in demand. The basis of such a flow is called just-in-time (JIT) production, where, through systematic techniques designed to minimize scrap and inventory, and essentially, all forms of waste, quality and productivity are increased, and costs are decreased. The aim of lean manufacturing is the elimination of waste in every area of production and includes customer relations, product design, supplier networks, and factory management. Womack and Jones (1996) describe lean thinking as the "antidote" to muda, the Japanese term for waste [13]. According to the study by Womack and Jones, the Japanese manufacturers were twice as effective as their US and other Western counterparts. 
More recently, six-sigma began to gain popularity in the USA in 1986, when Motorola Inc. introduced it as a means of measuring process quality using statistical process control. Six-sigma has been defined as an organized and systematic method for strategic process improvement and new product and service development that relies on statistical methods and the scientific method to make dramatic reductions in the customer defined defect rates [14]. Minimizing defects to the level of accepting close to zero was at the heart of the methodology, and focuses on reducing variation in all the processes of the organization. Motorola achieved amazing results through the application of six-sigma, from 1987 to 1997, achieving a total savings of \$US14 billion while sales enjoyed a fivefold growth during the same period [15]. Investing in six sigma programs is increasingly considered a mission-critical best practice, even among mid-sized and smaller firms. After the evolution of lean manufacturing, other pioneers have used the six-sigma process to achieve their company's unprecedented goal of a hundred-fold improvement in quality within five years reported that top organizations such as GE, ABB, Honeywell, Sony, Honda, and Ford have been using six-sigma to achieve business excellence [16].

A balanced scorecard is another methodology for CI generally used to clarify and update the business strategy, link the objectives of the organization to the annual budgets, allow organizational change, and increase the understanding of the company vision and mission statements across the organization. A balanced scorecard can be used to translate an organization's mission and vision statements into a broad set of objectives and performance measures that can be quantified and appraised, and measures whether management is achieving desired results [16]. About 50 per cent of the Fortune 1000 companies have a balanced scorecard system in place [17]. A balanced scorecard consists of managerial tools used for performance evaluation and the types of feedback it considers provide the guidance needed to continuously improve.

To overcome the weaknesses of one program or another, more recently, a number of companies have merged different CI initiatives together, resulting in a combined CI program that is more far reaching than any one individually. Lean six-sigma is the most well-known hybrid methodology, a combination of six sigma and lean manufacturing.

\subsection{Statistical Process Control}

Maintaining Quality in manufacturing requires the practice of quality control to reduce variability in quality characteristics of the product. Since variability can only be described in statistical terms, statistical methods play a central role in quality improvement efforts. Statistical Process Control is a scientific, data-driven methodology for quality analysis and improvement [2] [18]. As a result, statistical methods and their application in quality improvement have had a long history. Statistical Process Control (SPC) is a statistical approach for assisting operators, supervisors and managers to manage quality and to eliminate special causes of variability in a process [19]. The initial role of SPC is to prevent rather than identify product or process deterioration, but Xie and Goh (1999) suggest for its new role to actively identifying opportunities for process improvement [20]. The main tools in SPC are control charts. The basic idea of 
control charts is to test the hypothesis that there are only common causes of variability versus the alternative that there are special causes. By continuously monitoring the process, the manufacturing organization could prevent defect items to be processed in the next stage and to take immediate corrective action once a process is found to be out of control [21].

Walter Shewhart, at the Bell Telephone Laboratories, introduced the control chart in the 1920s to distinguish between inherent or normal variability [22], known as common cause variation, and variation due to a special cause which was popularized worldwide by Dr W Edwards Deming [23]. Shewhart charts are typically used to distinguish between variations due to special causes from variations due to common causes. Special causes are changes in the pattern of data that can be assigned to a specific cause. They are referred to unnatural variation due to events, changes, or circumstances that have not previously been typical or inherent in the regular process.

Common causes are problems inherent in the manufacturing system as a whole which are natural and expected. Processes that exhibit only common cause variation are said to be stable, predictable, and in statistical control. The process is said to be in statistical control when the special causes have been identified and eliminated. Shewhart charts can be used to monitor the process for the occurrence of special causes and to measure and reduce the effects of common causes [2]. These techniques include control charts, histogram distribution, Pareto analysis and correlation methods. Six-sigma is the latest development in the SPC effort. It incorporates many of the innovations in quality and efficiency improvement of the 20th century [4].

The business lesson of the 1980's was that Japanese firms, in their quest for global competitiveness, demonstrated a greater commitment to the philosophy of continuous improvement known as Kaizen management philosophy. Kaizen means continuous improvement involving everyone in the organization from top management, to managers then to supervisors, and to workers. It is using common sense and is both a rigorous, scientific method using statistical quality control and an adaptive framework of organizational values and beliefs that keeps workers and management focused on zero defects [24].

If a product is to meet or exceed customer expectations, generally it should be produced by a process that is stable or repeatable. More precisely, the process must be capable of operating with little variability around the target or nominal dimensions of the product's quality characteristics. Statistical process control methods extend the use of descriptive statistics to monitor the quality of the product and process. Using statistical process control we want to determine the amount of variation that is common or normal. Then we monitor the production process to make sure production stays within this normal range. That is, we want to make sure the process is in a state of control. The most commonly used tool for monitoring the production process is a control chart. Different types of control charts are used to monitor different aspects of the production process. A control chart (also called process chart or quality control chart) is a graph that shows whether a sample of data falls within the common or normal range of variation. 
A control chart has upper and lower control limits that separate common from assignable causes of variation. We say that a process is out of control when a plot of data reveals that one or more samples fall outside the control limits.

Statistical process control (SPC) (see Figure 1) is a set of statistical methods based on the theory of variation that can be used to control any process or outcome measured over time, usually with the intention to maintain a high level of performance. SPC combines rigorous time series analysis with graphical presentation of data, and can provide early insights into the data in a manner understandable to a wide range of audiences [23]. Using frequently measured data, SPC can be used to detect, early on, whether any change has taken place since the start of the intervention, long before results from a larger, summative evaluation are available. Such information can be used for purposes ranging from forming hypotheses about changes in outcomes to adapting elements of the intervention to increase quality. Today many organizations use statistical process control (SPC) as a means for obtaining higher product quality [18] [23] [25] [26].

\subsection{Ethiopian Manufacturing Industry}

Manufacturing industry in Ethiopia is at its infant stage [27]. However, in the last two decades several manufacturing industries including textile, Leather, Food, Pharmaceuticals, and Cement etc are flourishing mainly due to the conducive environment for investment created by the government. Ethiopia's Growth and Transformation Plan (GTP) of five years, 2010/11-2014/15, indicates the commitment of the government to provide basic infrastructure to develop four industrial cluster zones. The main purposes of developing industrial zones are to attract investment and investors by providing land with essential infrastructural services and creating an attractive environment for

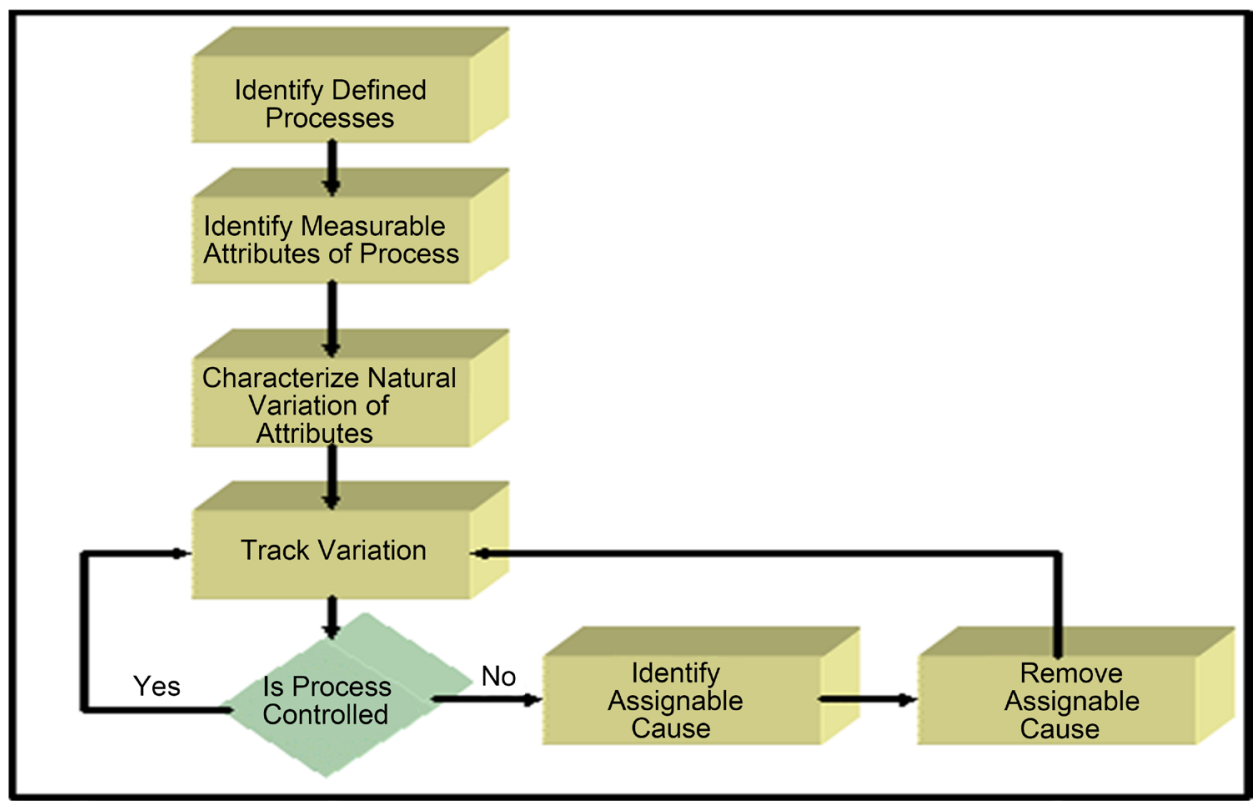

Figure 1. Schematic chart of Statistical Process Control (SPC). 
investors. Several strategies are indicated in the GTP to enable medium and large-scale manufacturing industries create competitive national economy by ensuring rapid and sustainable technological transfer, be export oriented and create a conducive environment for micro and small enterprises and agricultural developments. The strategies include attracting foreign investors to increase their investment in key industries by giving them all round and effective support, encourage industries which produce goods for the export market and substitute imports by giving them priority in accessing credit and other incentives [25]. Government-promotes industrial sectors such as textiles and garments, leather, sugar, cement, metals and engineering, chemicals, pharmaceuticals, and agro-processing through eligibility mechanisms for tax holidays and duty-free imported capital goods [25].

To increase the pool of adequately trained human resources for industries, the GTP indicated that focus will be placed on higher education and TVET to supply manpower equipped with knowledge and skill required by manufacturing industries. The research institutes will be strengthened to support the productivity of manufacturing industries. To this end, several promising measures are taken so far such as the 70 - 30 education policy, strengthening the capacity of Science \& Technology Universities, establishing several specialized research institutes including Textile institute, Leather institute, Ethiopian Kaizen institute etc.

As a result of the enabling environment created for manufacturing industry, the sector has already started attracting considerable investors and it is expected to continually attract both local and foreign investors. However, as emerging and inexperienced sector the issues of productivity, efficiency, competitiveness and quality will be challenges to the industry. In this regard, this work will investigate the experience and awareness of the manufacturing industries in quality control methods with emphasis to statistical process control tools.

\subsection{Rationale of the Study}

The emerging Ethiopian manufacturing industry sector is believed to face competitive environment for global market. In this regard, this study has evaluated the awareness and usage of quality control tools in the manufacturing industry and provides recommendations in fostering usage of quality improvement tools in the sector. The policy makers, manufacturing industries, the University and the country at large are beneficiaries of this study. This study hence would help to recommend policy directions so as to foster quality control tools such as SPC to be applied in manufacturing industries. Consequently, this could improve industries' competitiveness in the global market.

\section{Hypothesis of the Research}

We believe that there is a gap on awareness and usage of quality control tools in the Ethiopian manufacturing industries with emphasis to statistical process control that should be addressed as soon as possible. 


\section{Statement of the Problem}

Quality improvement is the key factor for the success and growth of any business organization.

Manufacturing industries are hence required to ensure that their processes are continuously monitored and product qualities are improved in order to survive and be able to provide customers with good products. However, the emerging Ethiopian manufacturing industry sectors are believed to face competitive environment for global market. Despite the enabling environment created for manufacturing industries in Ethiopia, as emerging and inexperienced sector the issues of productivity, efficiency, competitiveness and quality will be challenges to the industries. In this regard, this work has investigated the awareness and experience of the manufacturing industries in applying quality control tools with emphasis to statistical process control. In fact, we do believe that there is a gap on awareness and usage of quality control tools in the Ethiopian manufacturing industries. Hence, this study on the basis of empirical evidence would help to recommend policy directions so as to foster quality control tools such as SPC to be applied in manufacturing industries relevant to their processes.

\section{Objective of the study}

\subsection{General Objective}

To assess the awareness and usage of quality control tools with the emphasis on statistical process control in Ethiopian manufacturing industries.

\subsection{Specific Objectives}

The specific objectives are to:

- assess awareness of the industries to quality control tools with emphasis to SPC:

- determine the extent to which the producers are applying the techniques of SPC within their routine manufacturing operations:

- identify the most common techniques used, the scope of usage, and sources of information used in setting up the systems:

- identify constrains for applying quality tools such as SPC and

- recommend solutions to the constraints for applying quality tools.

\section{Materials and Methods}

\subsection{Data}

To acquired data on the nature and extent of quality control tools usage such as SPC among Ethiopian manufacturing industries, semi structured questionnaire method was employed to executive and technical managers of manufacturing industries of various size and specialism across the country. Available documents and reports related to quality control policy of the selected companies have been investigated. Hence, different manufacturing industries was considered from Tigray, Amhara, Oromiya, Southern nation, nationalities and people's region, Addis Ababa and Dire-dawa. 


\subsection{Methods}

Semi-structured questionnaire, with follow-up interviews, was conducted on a sample of manufacturing industries of various size and specialism across the country. The Questionnaire addressed awareness, usage and experience of the manufacturing industries on quality control tools such as SPC methods as well as constraints/challenges of industries for introducing quality control tools. This work relies on qualitative methods to collect and compile the empirical evidence. It was based on in-depth interviews with the company executives and/or quality control directors and internal company's documents were scrutinized. Stratified random sample method by region was used to select sample of industries for the study. Regional sample size was considered to ensure the proportionality of the total amount of industries in the respective region. Exploratory method and descriptive statistics was employed for data analysis.

\section{Results}

The number of manufacturing industries involved in this study was 44 and yielding a response rate of $90 \%$. The industries that responded to the study varied in products and size. Of the sampled manufacturing industries about $59.1 \%$ are from Oromiya and Addis Ababa regions together (Figure 2). The manufacturing industries in Ethiopia consist of a number of sectors such as textile, leather, food, pharmaceuticals, and cement industry etc. The profile of the organizations with respect to nature of industry (types) and the number of employees are shown in Table 1 and Table 2.

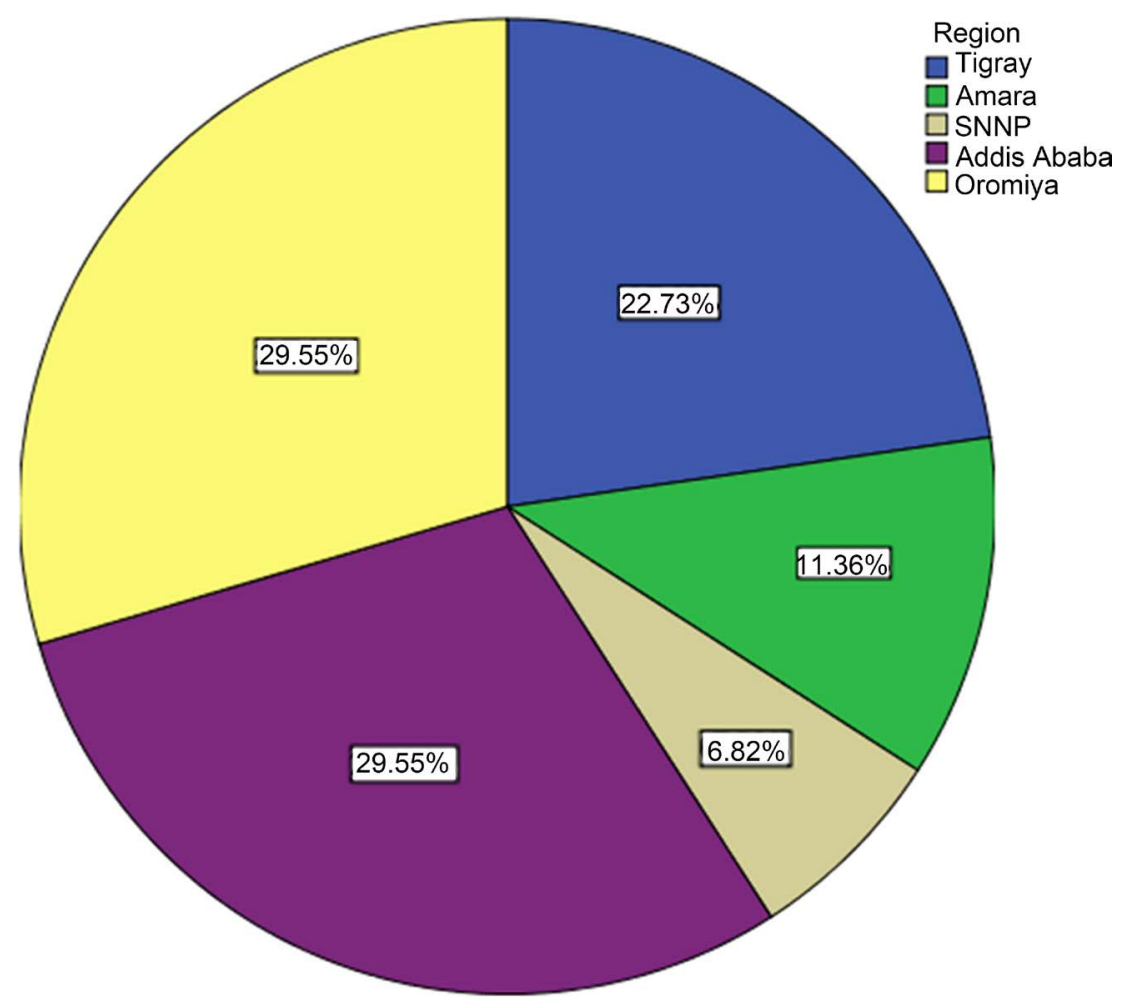

Figure 2. Distribution of Manufacturing Industries (MIs) by regions in Ethiopia, 2016. 
Table 1. Distribution of manufacturing industries by type in Ethiopia, 2016.

\begin{tabular}{ccc}
\hline Serial No. & Type of Industry & Percentage \\
\hline 1 & Food and beverages & $31.81 \%$ \\
2 & Garment and Textile & 31.81 \\
3 & Metals and Engineering & $25 \%$ \\
4 & Cement & $4.5 \%$ \\
5 & Others & $6.8 \%$ \\
\hline
\end{tabular}

Table 2. Distribution of the number of employees in the entire selected manufacturing industries in Ethiopia, 2016.

\begin{tabular}{ccc}
\hline S. No. & Number of Employees Category & Percent \\
\hline 1 & $51-250$ & 22.7 \\
2 & $251-500$ & 31.8 \\
3 & $501-1000$ & 18.2 \\
4 & More than 1000 & 22.7 \\
5 & Missing & 4.5 \\
Total & Total & 100 \\
\hline
\end{tabular}

\subsection{Awareness of Quality Control Tools with Emphasis to SPC}

Despite the enabling environment created for manufacturing industries in Ethiopia, as emerging and inexperienced sector the issues of productivity, efficiency, competitiveness and quality will be challenges to the industries. In this regard, this work has investigated the awareness and experience of the manufacturing industry in quality control methods with emphasis to statistical process control tools. Hence, due to the importance of quality control tools in industries, the term quality awareness was used to determine the number of organizations which are aware of these practices. Awareness is the state or ability to perceive, to feel, or to be conscious of events, objects or sensory patterns.

In line with this, Figure 3 shows that $100 \%$ of the respondents said that the importance of quality control tools is very important to their organizations' productivity and quality improvement (this response was the highest degree of importance asked to the respondents with respect to quality awareness they had). The degree of awareness in this study was classified as important, less important, very important and not at all.

This study also attempted to determine how often awareness training is given regarding quality control tools to improve the quality of the products produced by their respective industries. Hence, the responses indicated that $48 \%$ of the industries are usually receiving awareness training on quality control tools, $39 \%$ of the respondents have reported that as they received on some times and about $14 \%$ were receiving on rarely basis (Figure 4 ). 
Moreover, this study has covered more questions related to awareness and usage of quality control tools. These questions can be listed but not limited to these issues:

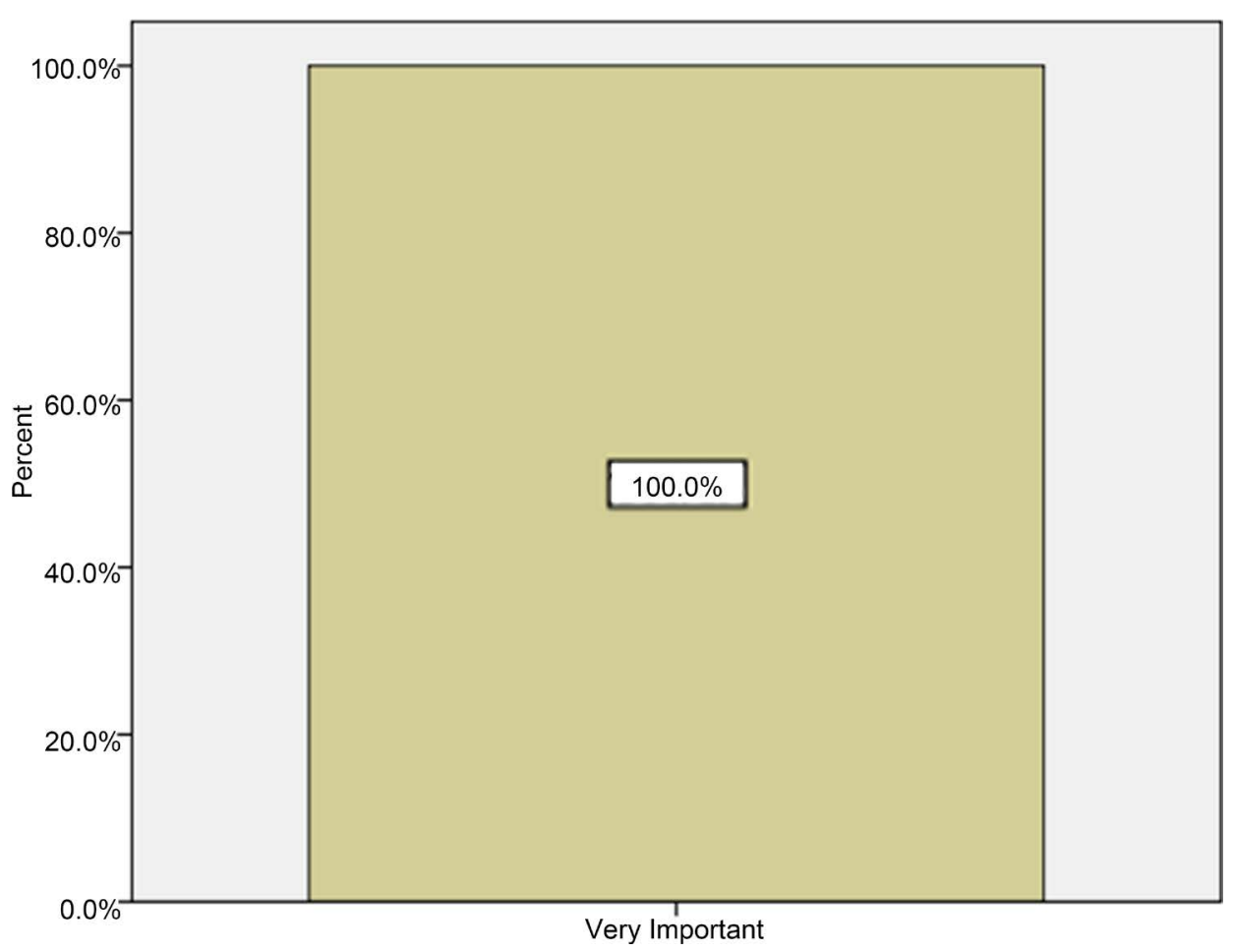

Figure 3. Do you think that QCS is important for your Organization?

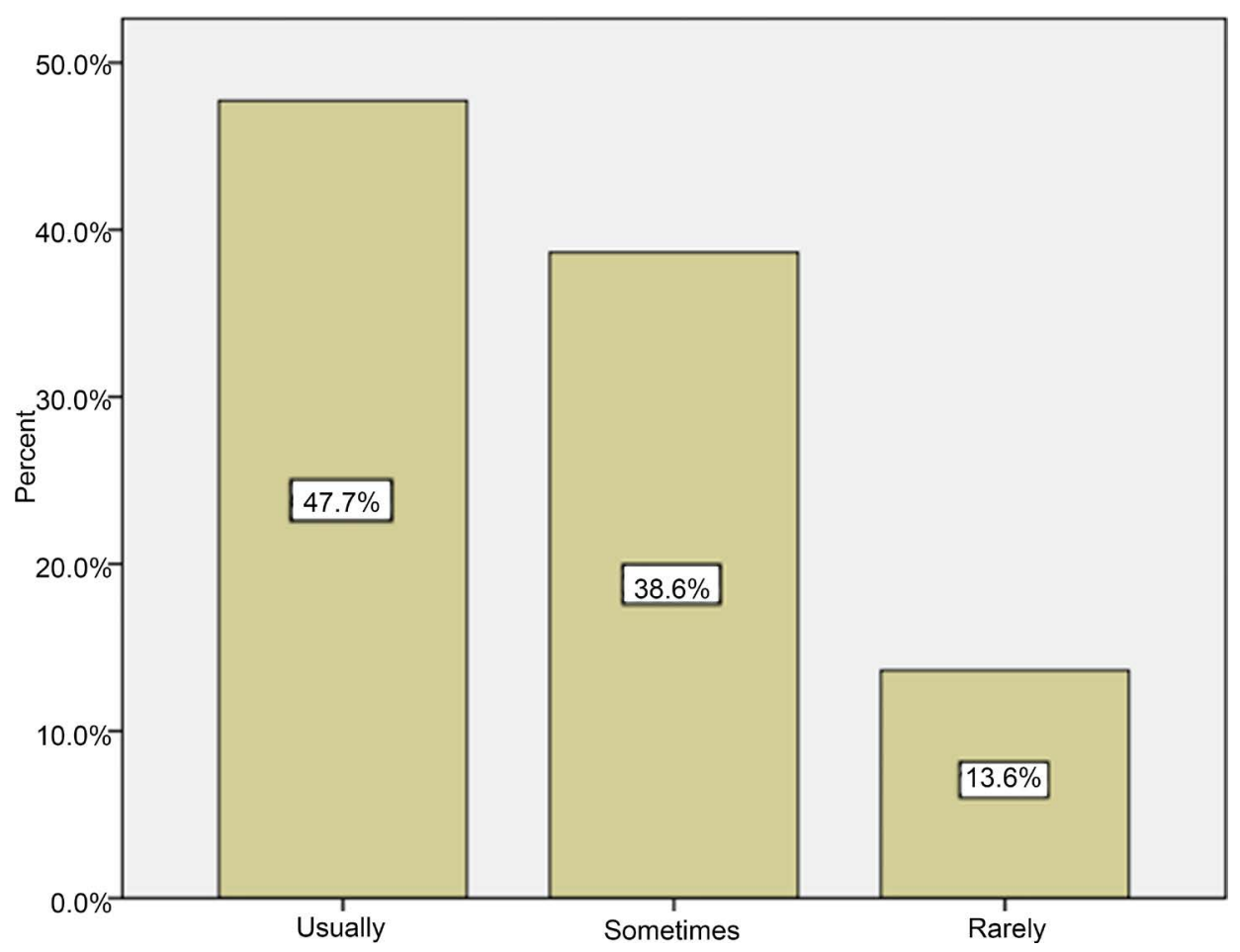

Figure 4. Distribution of How often awareness training is given regarding QC tools? 
- Is there any department working on quality control system (QCS) in your industry?

- How QCS is organized in your industry?

- Do you have specific QC instruments or systems?

- QC methods in your organization are practiced on? (that is input materials, output and/or products, at all levels of the process)

- To what extent do you think QCS is working in your industry?

- Challenges for using QC tools

- How long training opportunity is given for quality control professionals?

- QC training opportunity if any is given, where?

- How far do you think that QC practice helps your industry to be productive?

- The QC systems implemented in our organization are designed by?

- Is there any Research department working on productivity, quality and profitability of your organization?

- Do you have experience in using statistical methods as QC mechanism?

- Do you think that the quality control department fully recognizes the importance of SPC as QC tools?

This study has also made an effort to assess whether there exist any department working on quality control system and how quality control system is organized in their respective industries. Accordingly, the responses indicated that more than three forth of the industries (88\%) have established a department working on quality control system and similarly $68 \%$ of the industries have noted that the quality control system were organized by department, $27 \%$ of the industries were organized across different departments and $5 \%$ of the industries were organized at expert level (Figure 5 and Figure 6).

Furthermore, the responses indicated that $86 \%$ of the industries have reported that they do have specific quality control instruments with their respective industries (Figure 7).

Manufacturing industries have also been asked to determine the level of awareness on how quality control methods used to practice with regard to their procedures. Of the respondents about $95.5 \%$ have noted that quality control methods are practiced at all levels starting from the raw materials and about $4.5 \%$ of the industries have experience to practice on finished products (Figure 8). In line with this, $100 \%$ of the respondents said that quality control practice help to improve their organization productivity (Figure 9). This study has also covered several questions with regard to quality control professionals to determine whether they are aware and practice quality control tools to meet customer satisfaction. In line with this, of the industries $84.1 \%$ have reported that short term training opportunity is given to quality control professionals, $4.5 \%$ both short term and long term is given and $11.4 \%$ no training opportunity is given (Figure 10). Similarly, respondents were asked where quality control training is given to their employees. Majority of the respondents (45.24\%) have indicated that quality control training would be given in both within country and organization (Figure 11).

Furthermore, this study was also interested to know that who designed the quality control system implemented in your organization. Majority of the respondents (35.9\%) 


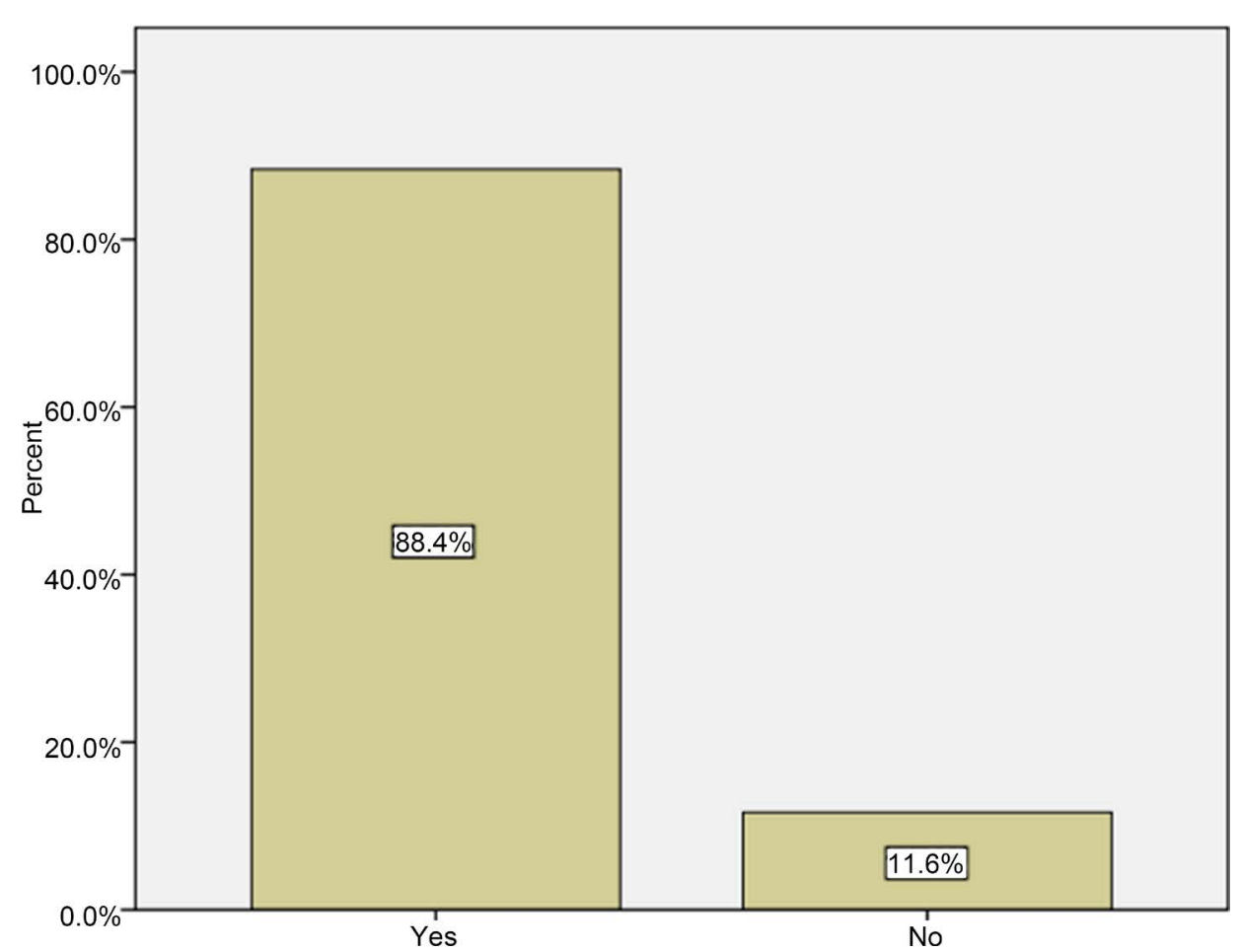

Figure 5. Is there any department working on QCS in your industry?

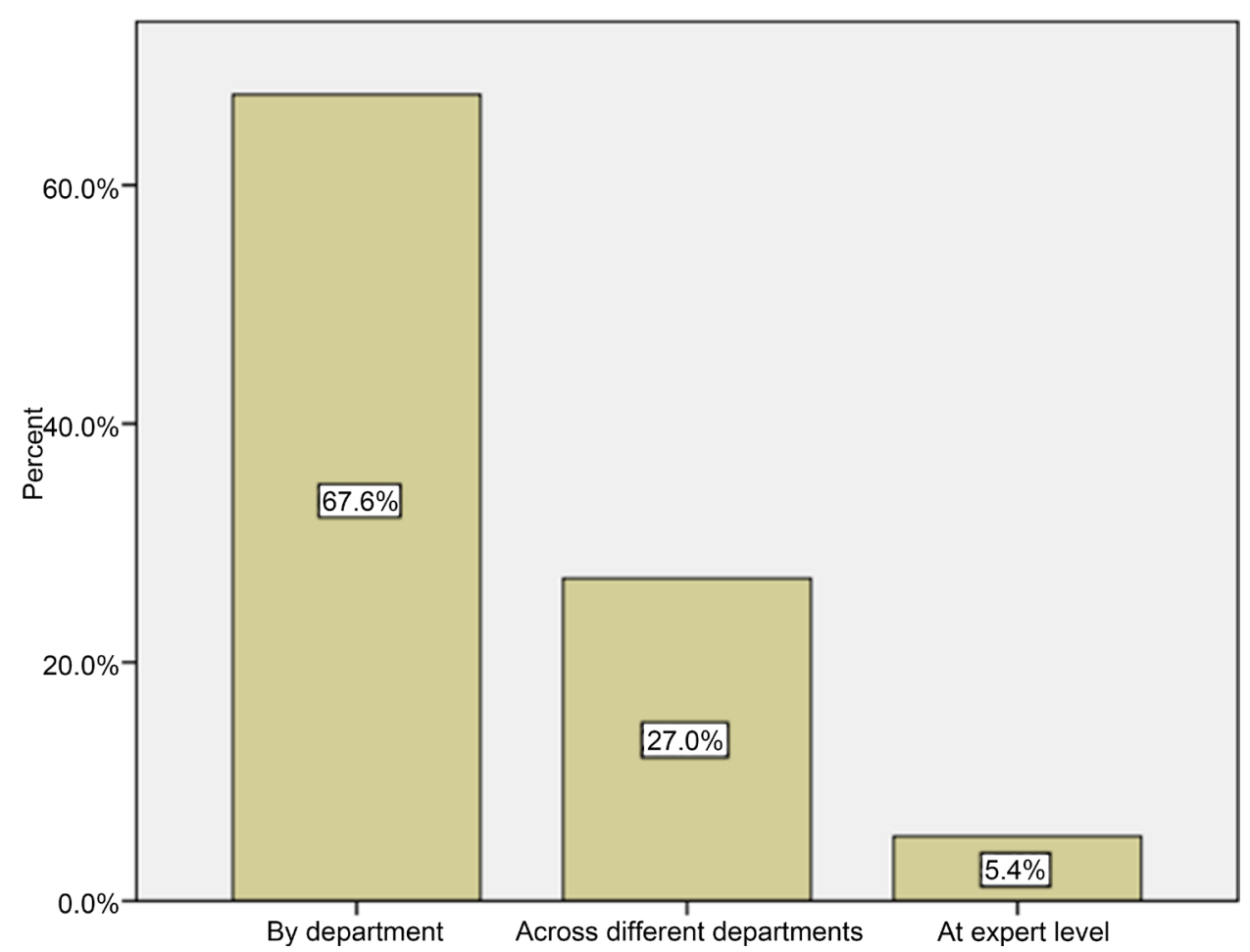

Figure 6. How QCS is organized in your industry?

have indicated that the quality control system was designed by expatriates (Figure 12). In connection to this, about $75 \%$ of the respondents have noted that there is no research 
department working on productivity, quality and profitability of their organization (Figure 13).

\subsection{Usage of Quality Control Tools for Quality Management}

Quality control tool may be described as a method which has a clear role and defined

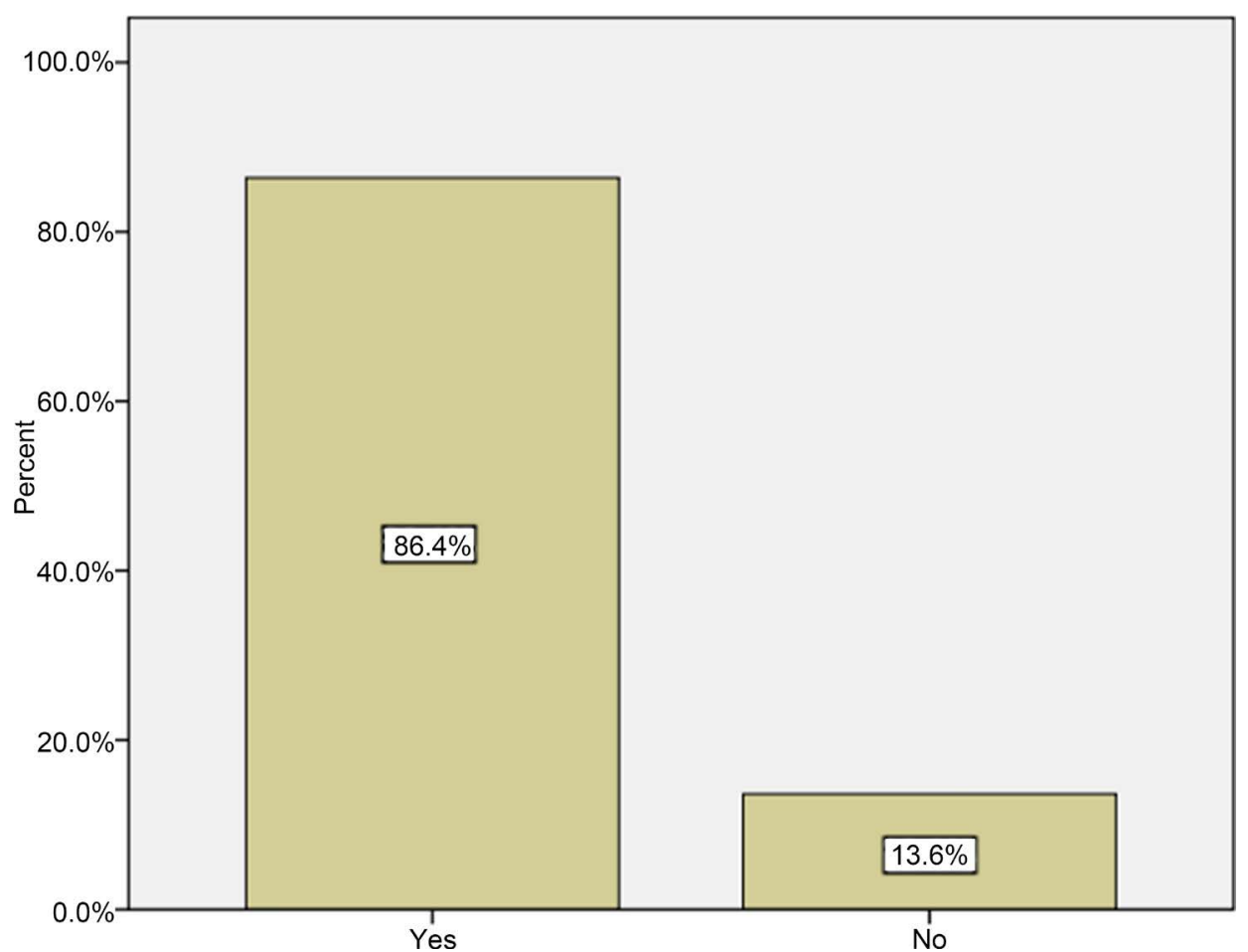

Figure 7. Do you have specific QC instruments or systems?

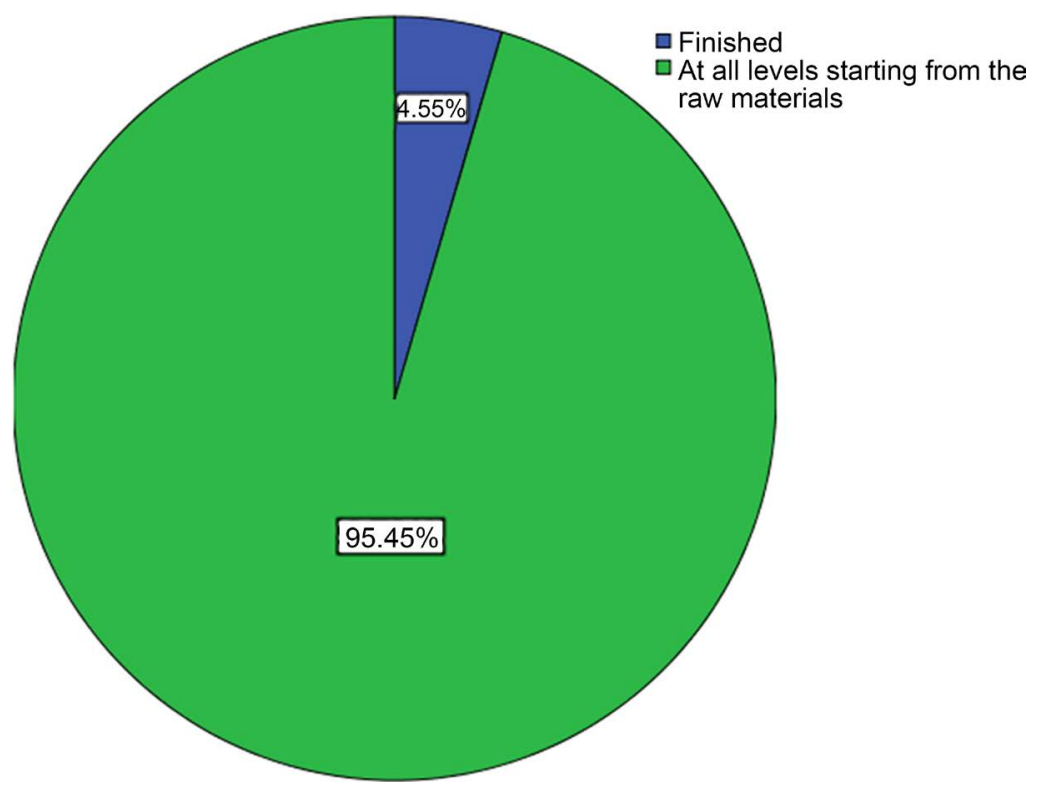

Figure 8. QC methods in your organization are practiced on? 


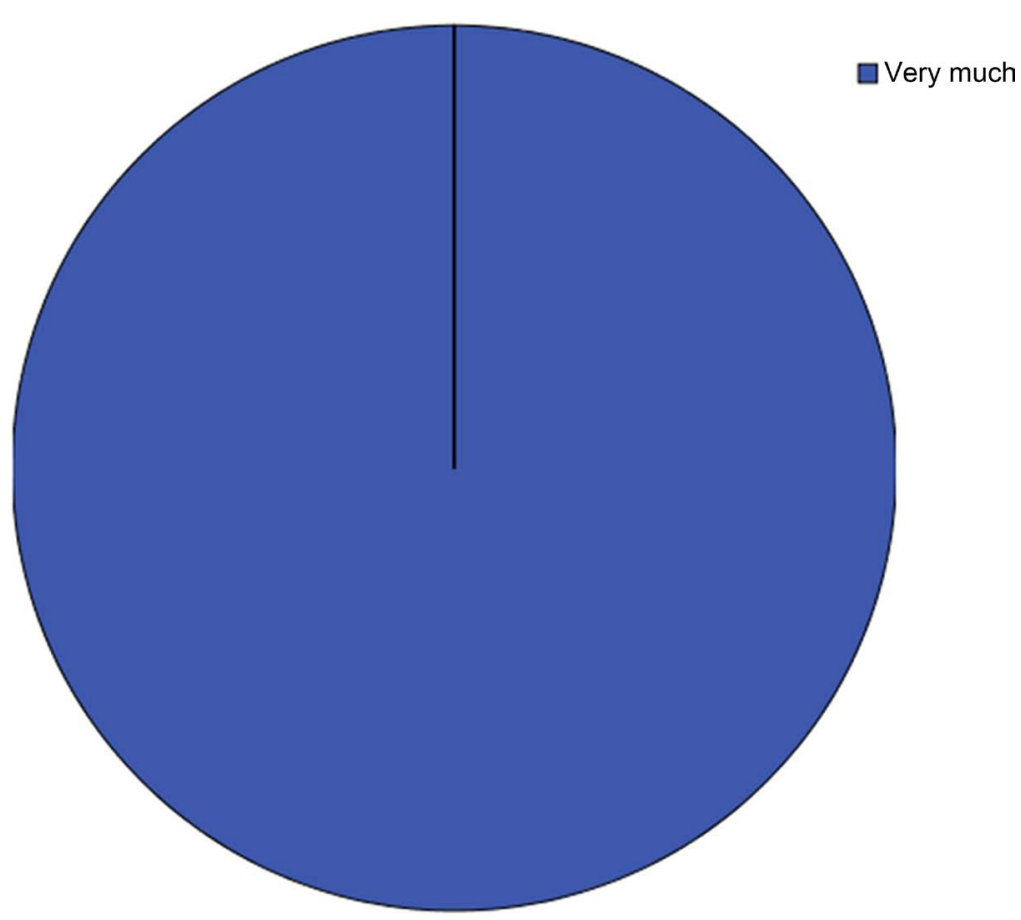

Figure 9. How far do you think that QC practice helps yours industry to be productive?

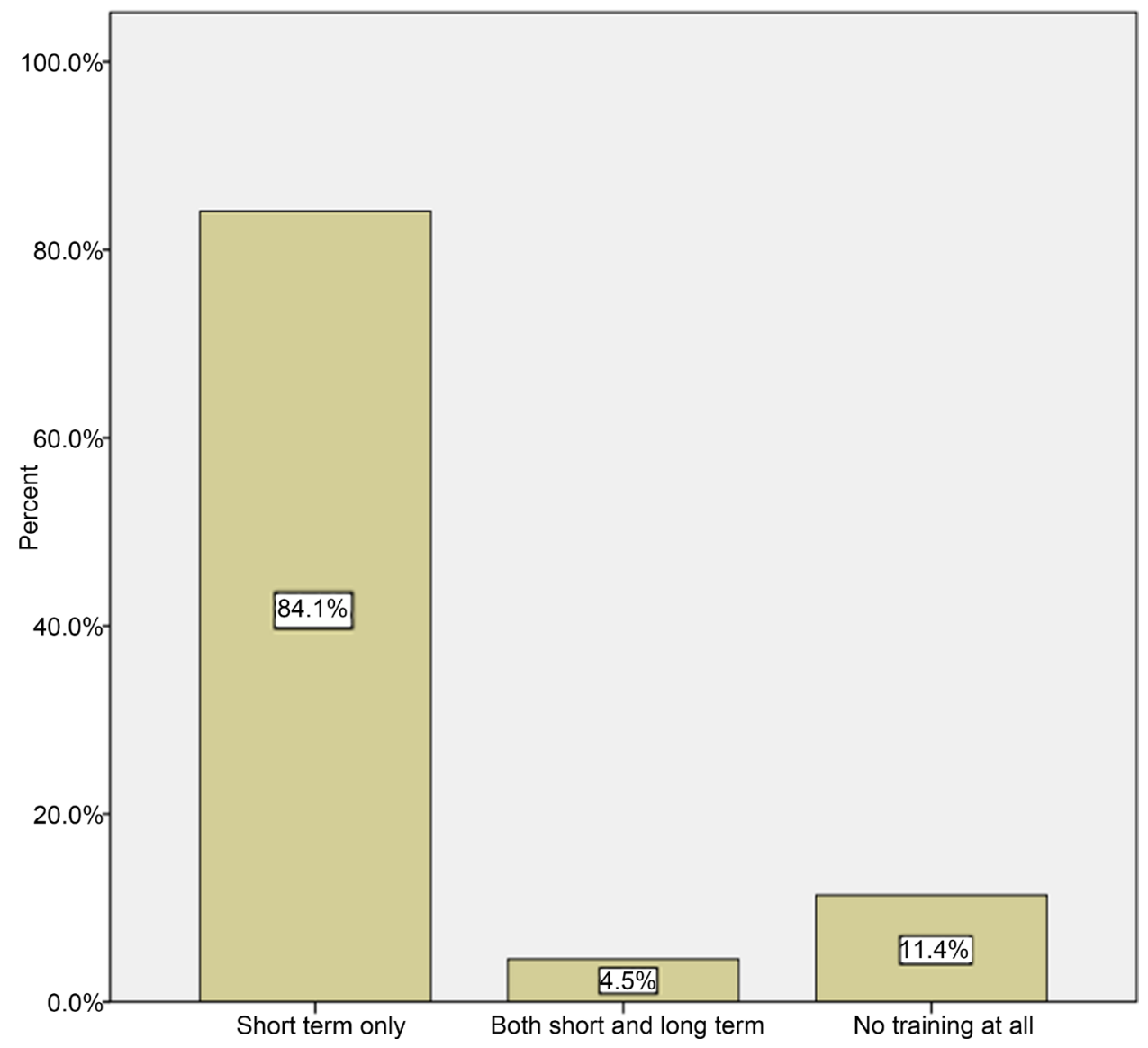

Figure 10. How long training opportunity is given for quality control professionals? 


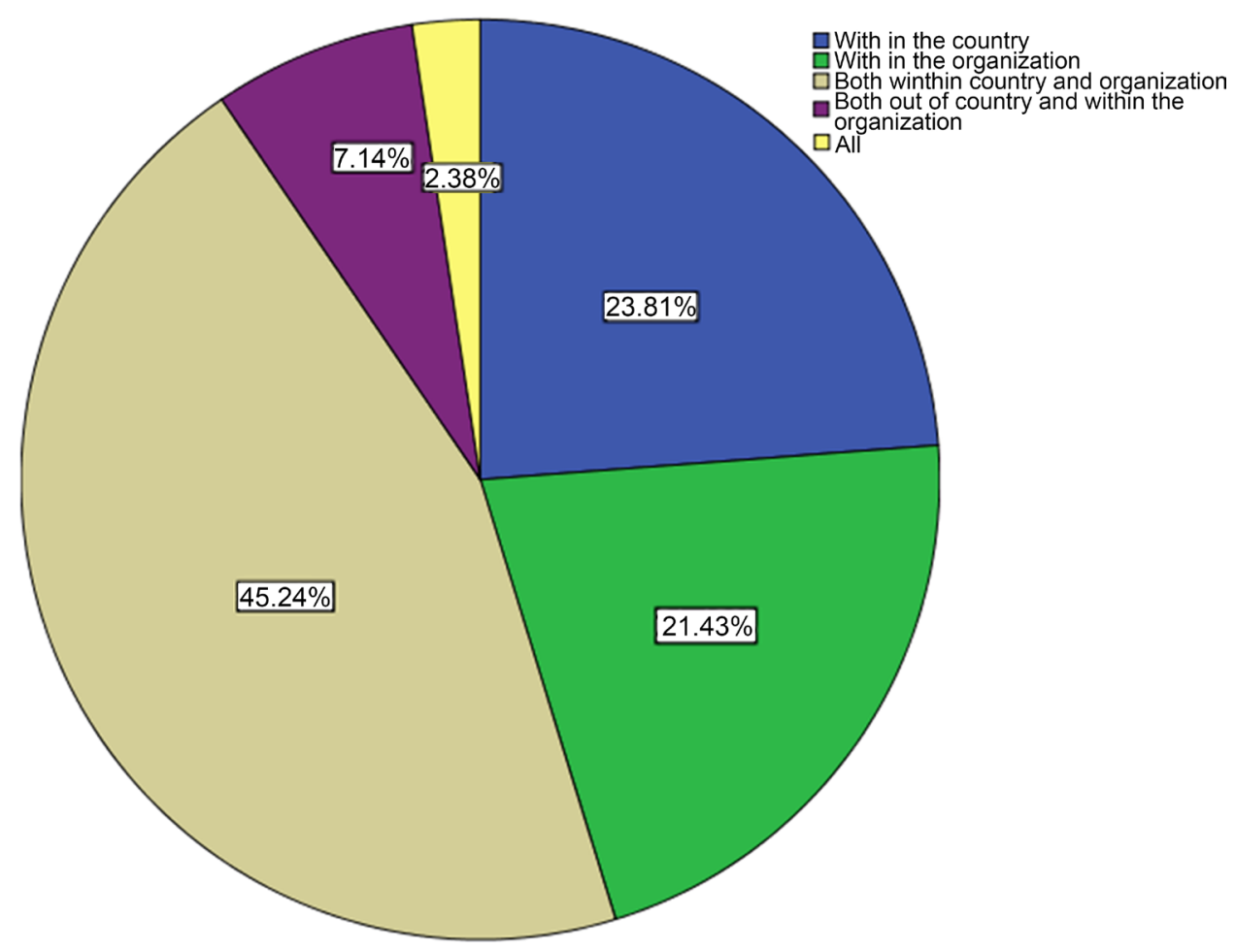

Figure 11. QC training opportunity if any is given, where?

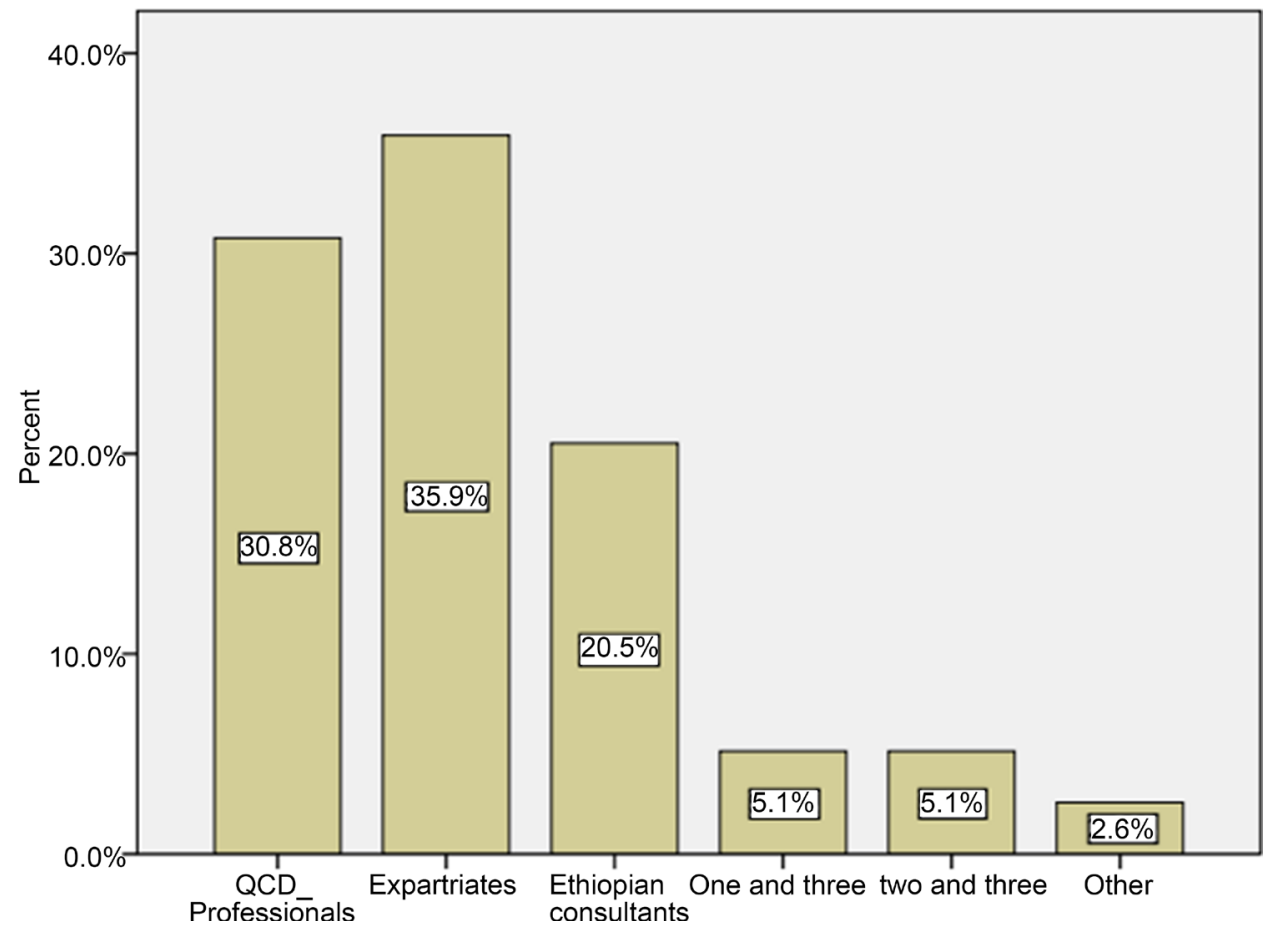

Figure 12. The QC systems implemented in our organization are designed by?

application; it is often limited in its focus and can be and usually is used on its own (e.g., fish-bone diagram). For this several questions were asked to organization. First 
was awareness of SPC and second was usage of statistical process control (SPC). This study revealed that majorities of the respondents didn't have experience in using statistical methods as quality control mechanism (Figure 14). In line with this, most of the

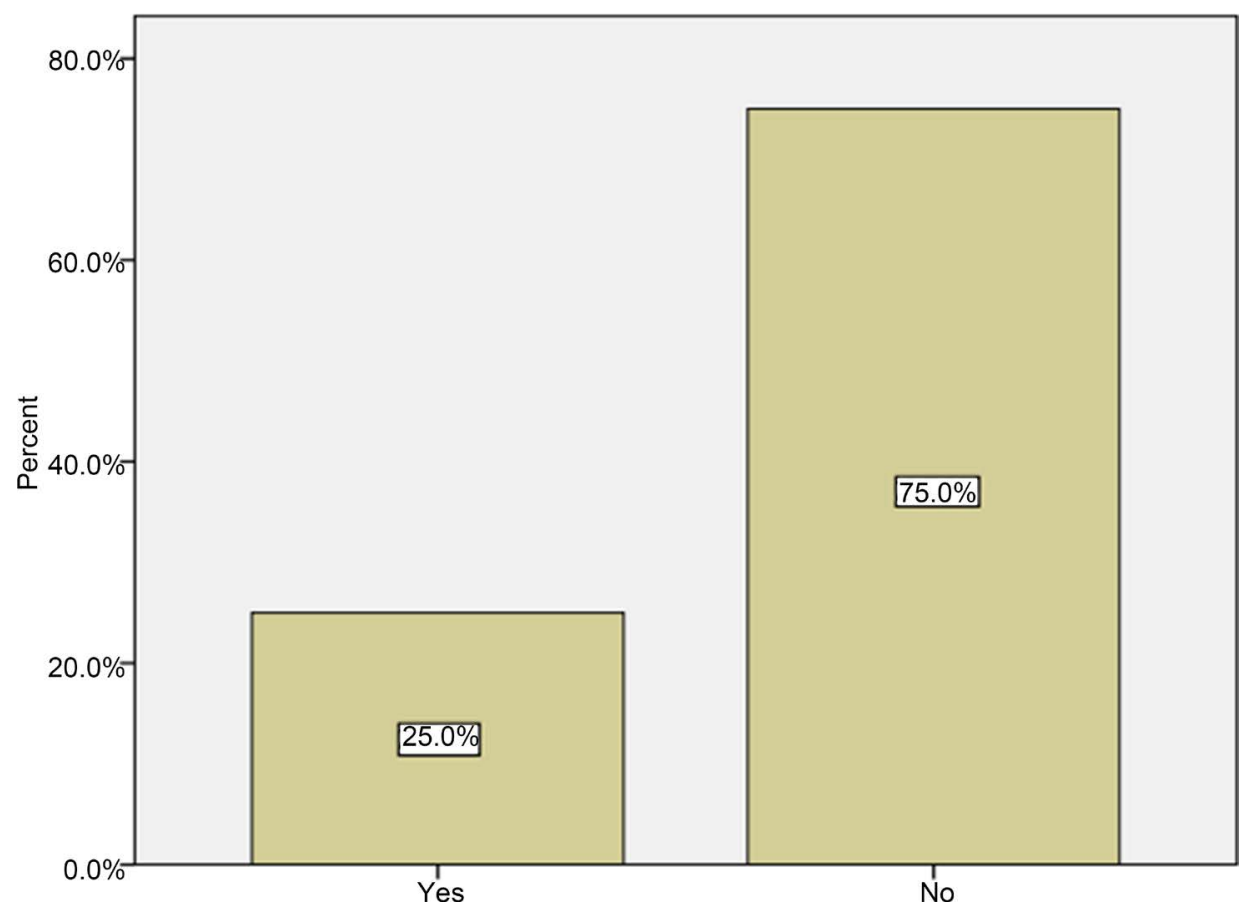

Figure 13. Is there any research department working on productivity, quality and profitability of your organization?

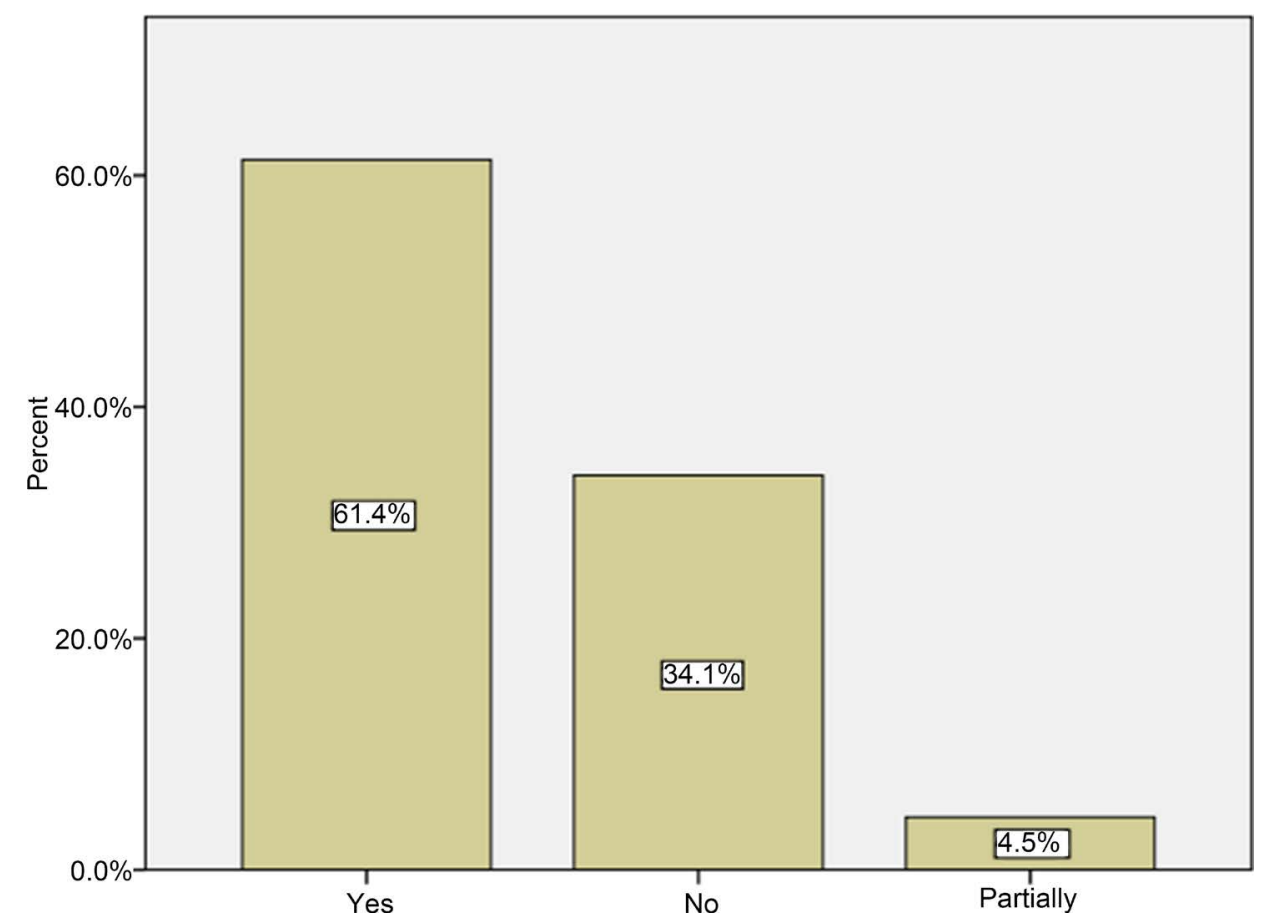

Figure 14. Do you have experience in using statistical methods as QC mechanism? 
quality department of the industries did not fully recognize the importance of statistical process control as quality control tools (Figure 15).

Respondents were also asked if any training is given concerning SPC. Majority of the respondents $(61.4 \%)$ have indicated that they did not get any training concerning SPC (Figure 16). This is mainly due to lack of awareness on statistical process control as 65.1\% of respondents had noted below in Figure 17.

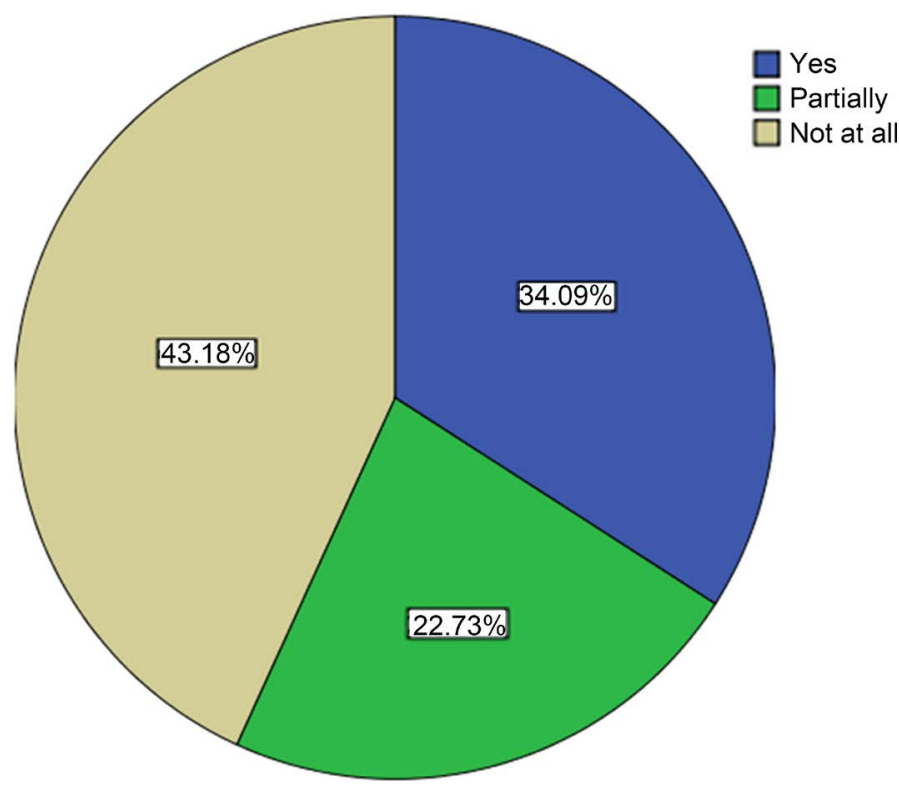

Figure 15. Do you think that the quality control dept fully recognize the importance of SPC as QC tools?

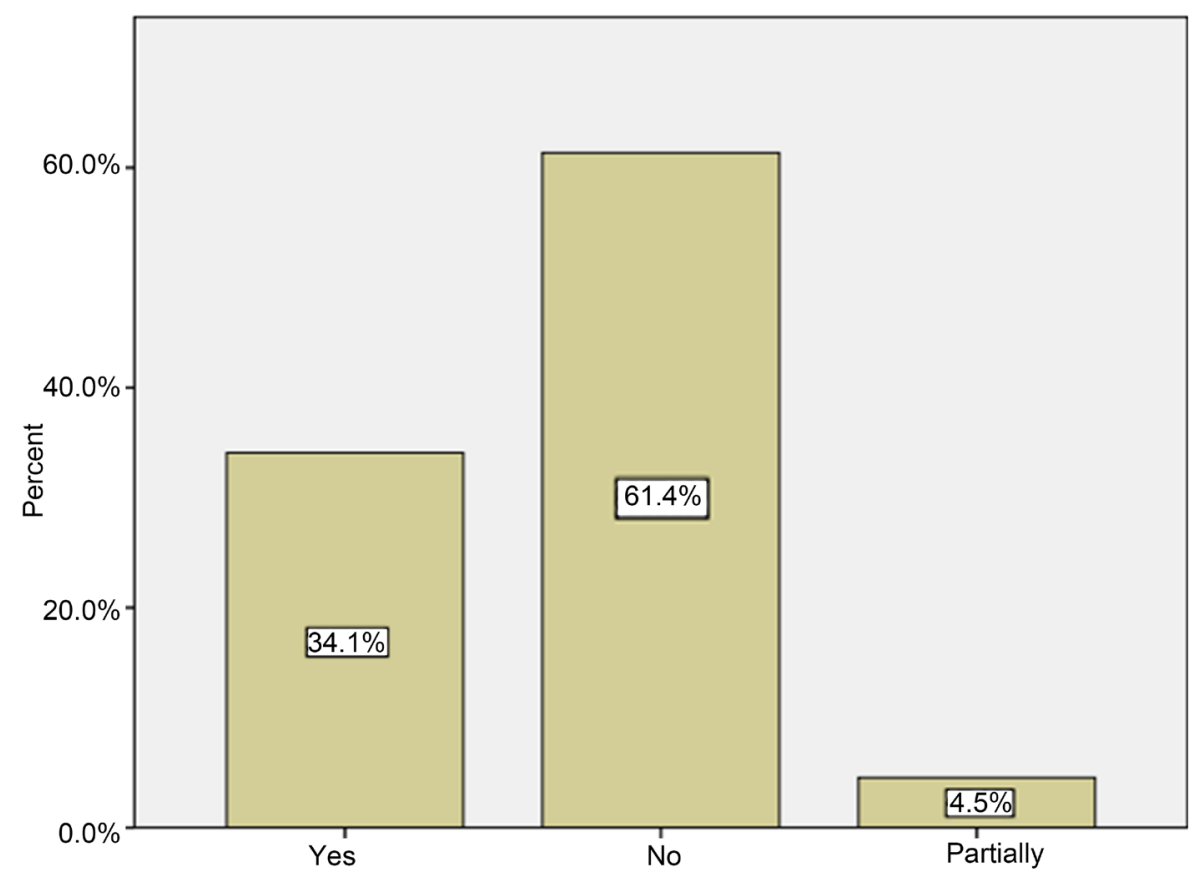

Figure 16. Is there any training that is given to your organization concerning SPC? 


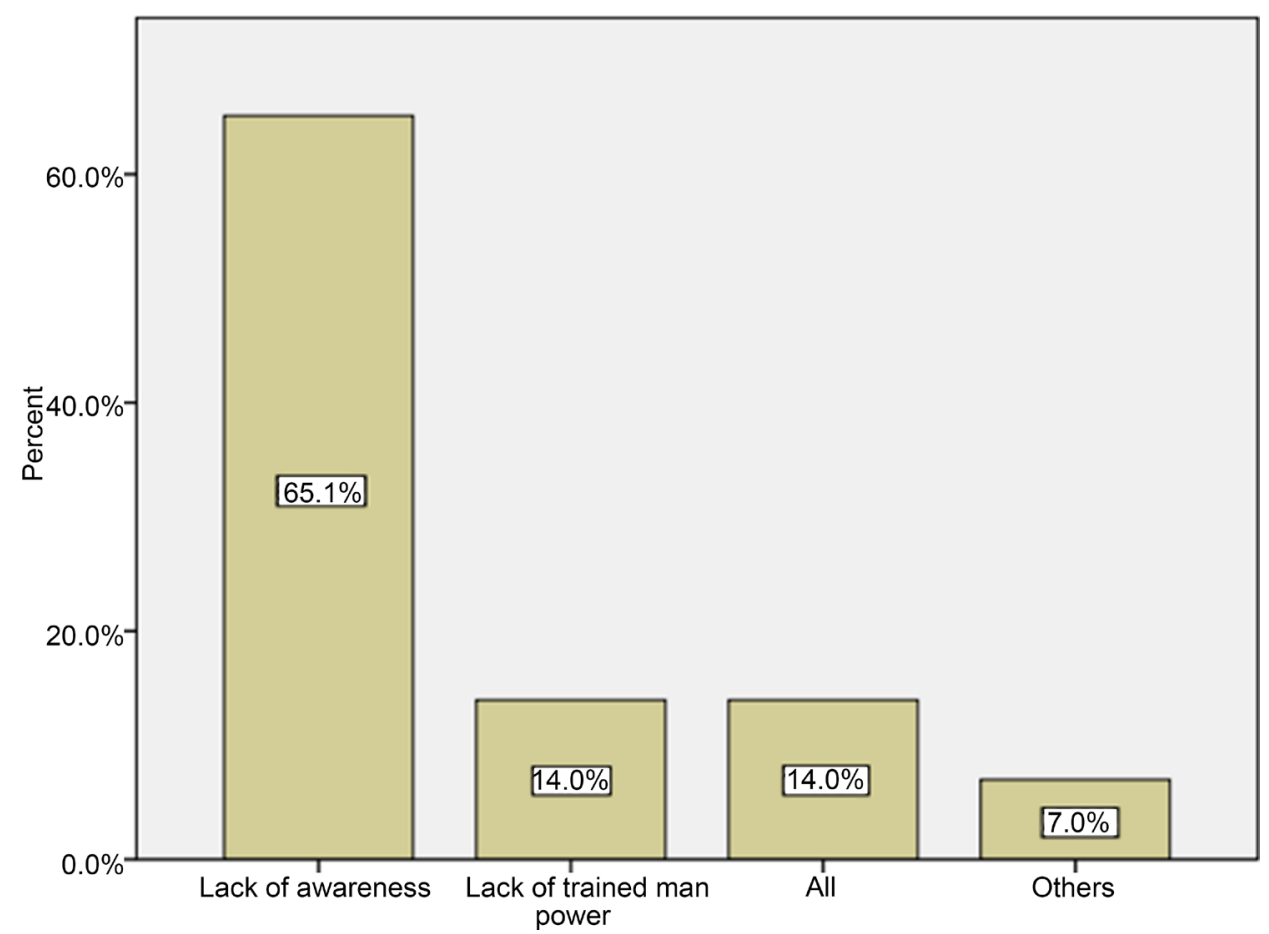

Figure 17. Are there any challenges that limit your organization in using SPC as QC?

Quality control professionals were asked to what extent that quality control system is working in their industry. Accordingly, majority of the respondents (54.5\%) have indicated that quality control system is working to some extent in their respective industries (Figure 18). In line with, respondents have mentioned that the challenges for using quality control tools is that lack of motivation and awareness of the management, shortage of man power in the area, and others together would make it difficult to quality control tools in their organization (Figure 19).

Furthermore, most of the respondents (93.2\%) have indicated they want to get training on statistical process control while the rest were not willing to get training on SPC (Figure 20).

Moreover, the Pareto chart below also used to analyze the challenges that could hinder to apply quality control tools. The chart hence discovered that $80 \%$ of the problems found almost in all industries not to apply quality control tools are mainly due to lack of awareness and motivation of top managements, shortage of skilled man power in the area, and lack of quality control tools together would make it difficult to apply quality control tools in their organization (Figure 21).

$\mathrm{Al}$ most all quality departments of the industries did not fully also recognize the importance of statistical process control as quality control tools. Majority of the respondents $(62 \%)$ have indicated that they did not get any training concerning SPC. The Pareto chart below hence used to analyze the challenges that could hinder the application of statistical process control tools in their industries. The chart therefore revealed that $80 \%$ of the problems found almost in all industries not to apply statistical process control tools are mainly due to lack of awareness, shortage of skilled man power in the 
area, and others together would make it difficult to apply statistical process control tools in their organization (Figure 22).

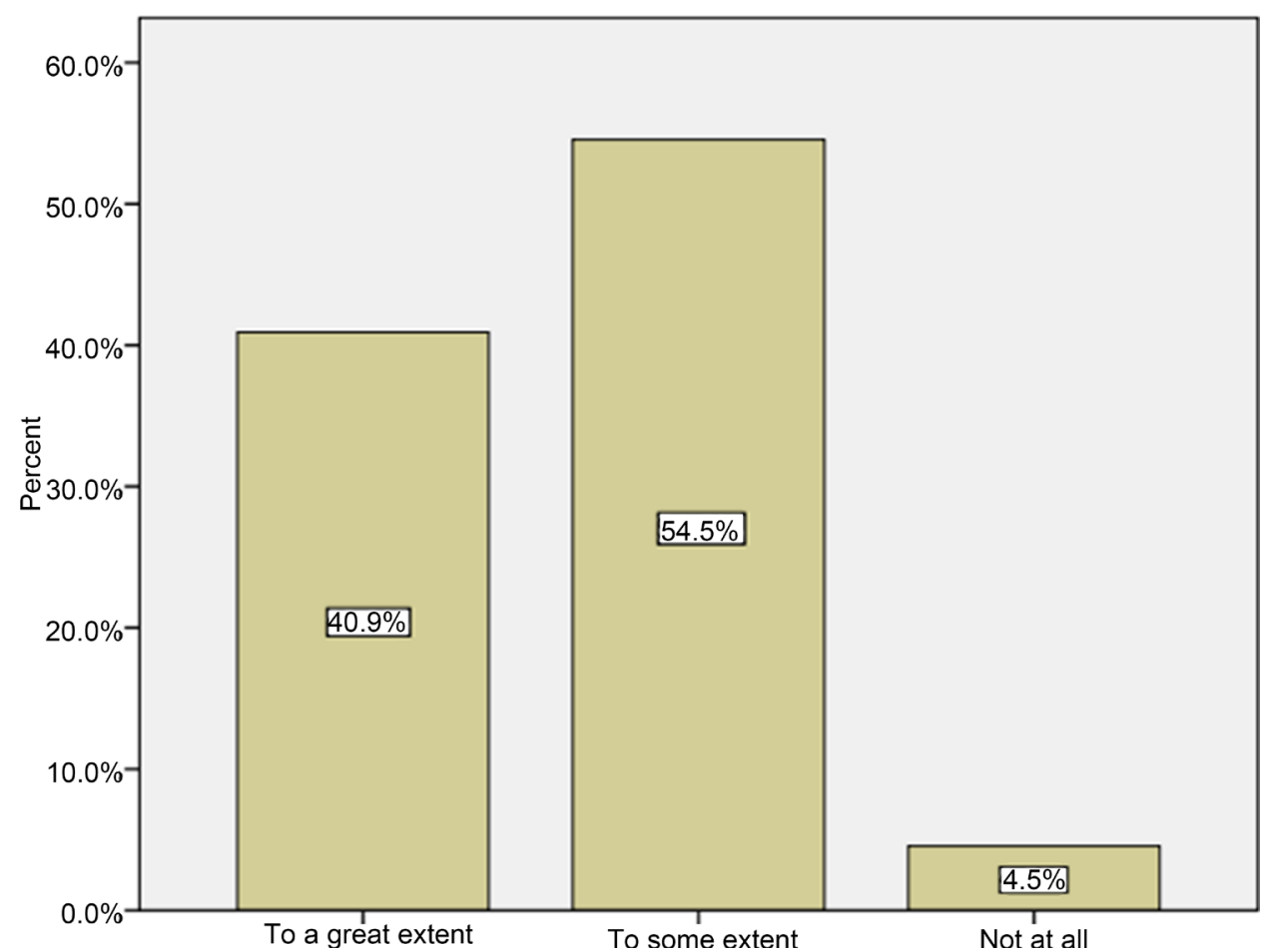

Figure 18. To what extent do you think QCS is working in your industry?

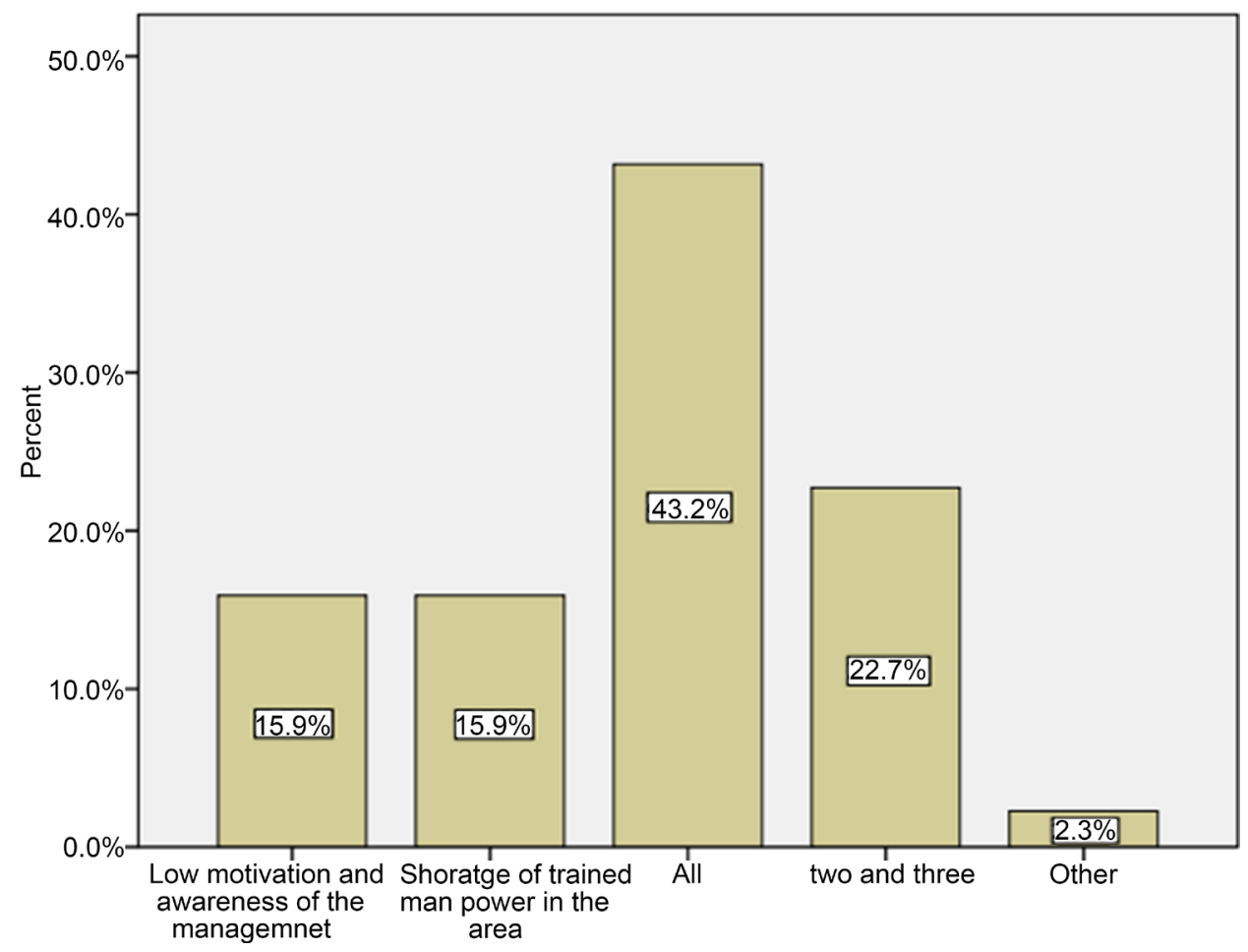

Figure 19. Challenges for using QC tools. 


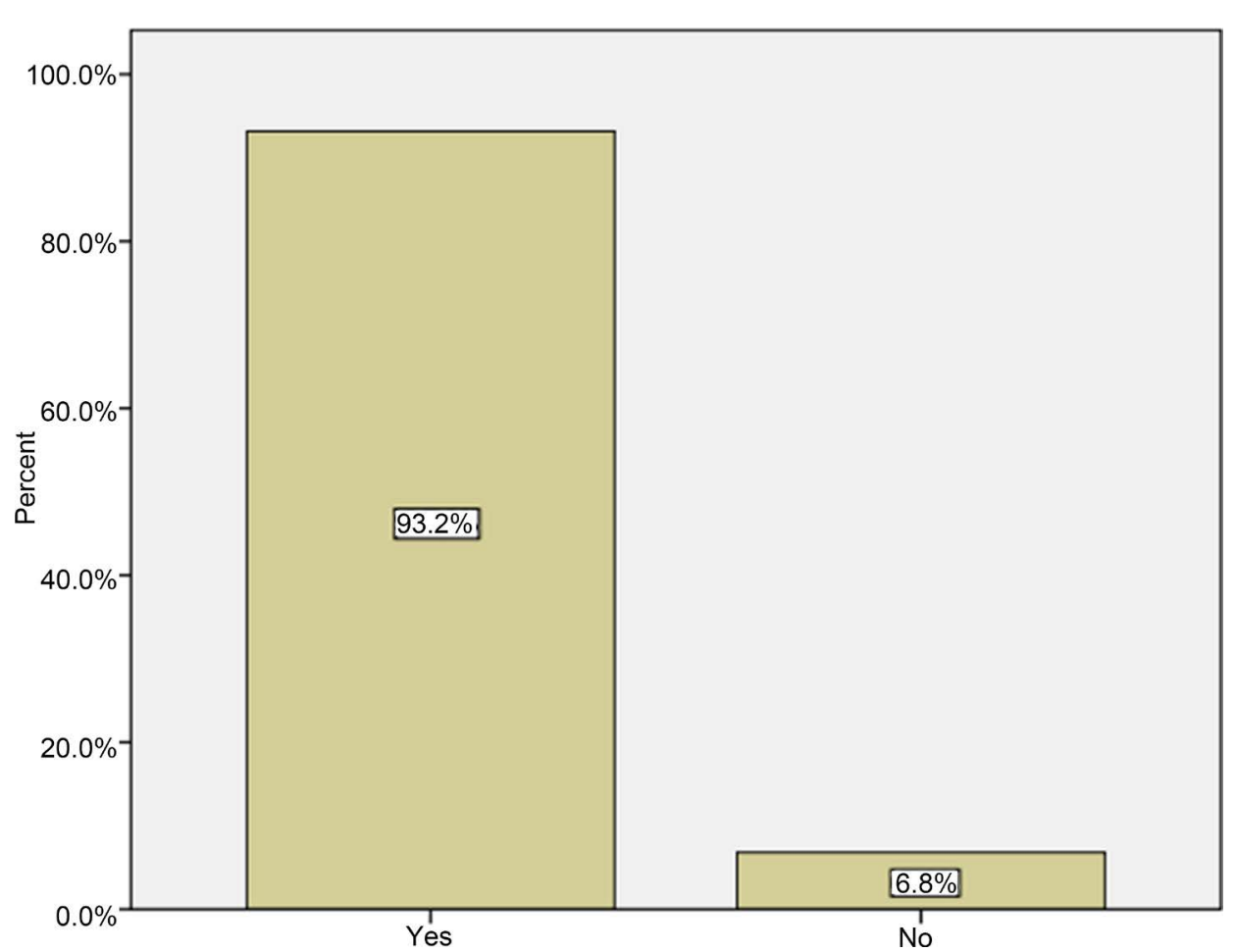

Figure 20. Do you want to get training on SPC?

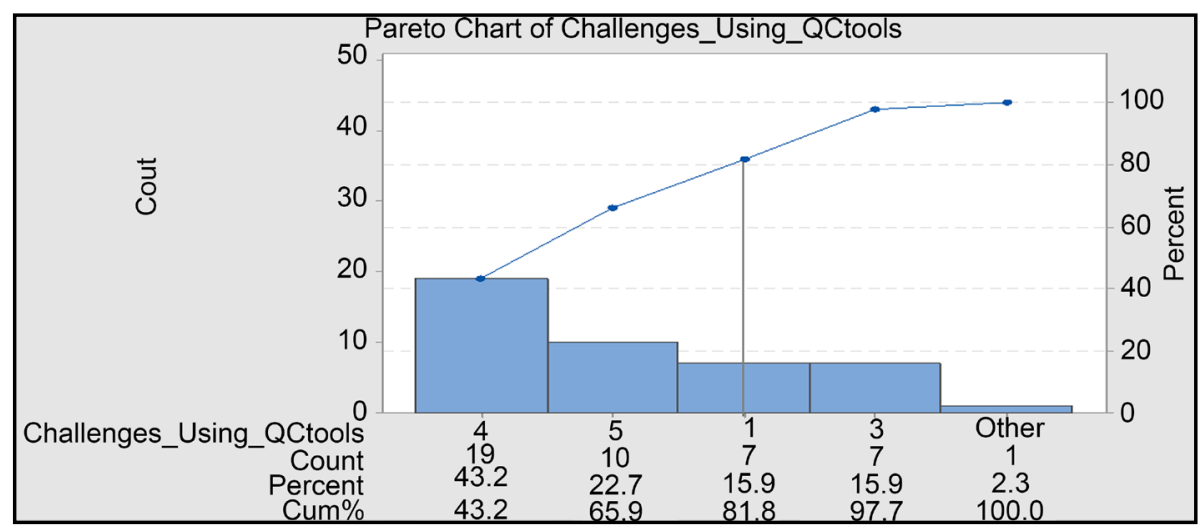

Figure 21. Pareto Chart of challenges for using quality control tools

\section{Discussions}

Globalization has made manufacturing industries moving towards three major competitive grounds namely quality, cost, and responsiveness. Manufacturing industries are therefore required to ensure that their processes are continuously monitored and product qualities are improved in order to survive and be able to provide customers with good products. However, the emerging Ethiopian manufacturing industry sectors are believed to face competitive environment for global market. Despite the enabling environment created for manufacturing industries in Ethiopia, as emerging and inexperienced sector the issues of productivity, efficiency, competitiveness and quality will be challenges to the industries. In this regard, this work has investigated the awareness 


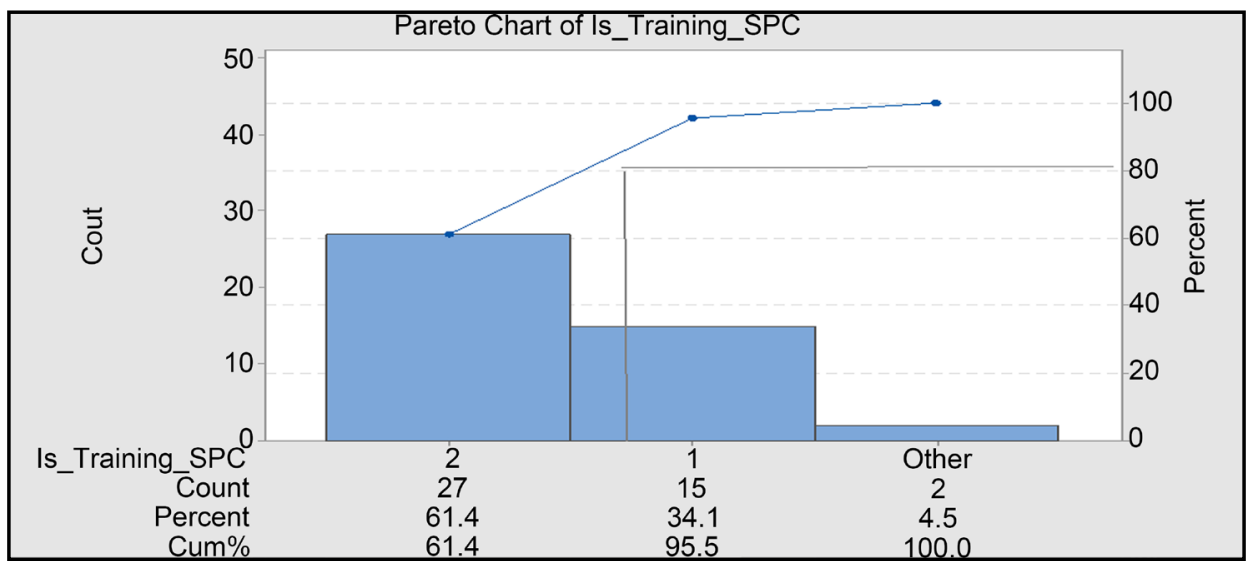

Figure 22. Pareto chart whether departments fully recognize the importance of SPC.

and experience of the manufacturing industries in quality control tools with emphasis to statistical process control tools.

This study showed that $100 \%$ of the respondents said that the importance of quality control tools is very important to their organizations' productivity and quality improvement (this response was the highest degree of importance asked to the respondents with respect to quality awareness they had) (Figure 3). The degree of awareness in this study was classified as important, less important, very important and not at all. This finding is consistent with a systematic review of study conducted by Varsha M. Magar and Vilas B. Shinde, 2014 ensured that the use of quality control (QC) tools help to improve the quality level of manufacturing processes by applying it [28]. It has been also stated that quality control tools are the means for collecting data, analyzing data, identifying root causes and measuring the results. All of these tools together can provide great process tracking and analysis that can be very helpful for quality improvements. This indicates that QC tools are most helpful in troubleshooting issues related to quality. Furthermore, a study on total quality control of manufacturing of Liners by applying statistical process control technique had revealed that process capabilities are improved by decreasing the rejection rate from $6.52 \%$ to $4.62 \%$ due to implementation of SPC. A Pareto analysis for comparative results had also revealed that there exists reduction in wastage of units produced [29].

This study also attempted to determine how often awareness training is given regarding quality control tools to improve the quality of the products produced by their respective industries. Hence, the responses indicated that $48 \%$ of the industries are usually receiving awareness training on quality control tools, $39 \%$ of the respondents have reported that as they received on some times and about $14 \%$ were receiving on rarely basis (Figure 4). An empirical study that examined quality awareness and developments as well as identifies factors affecting product quality based on a survey conducted in a total of 35 Ethiopian medium and large scale manufacturing industries has analyzed that negatively responded companies for the basic quality elements using $\mathrm{Pa}$ reto diagram [30]. The study indicated that there is a severe problem in relation to introducing incentive programs related to quality improvement, employment of PDSA 
cycle, absence of information about quality of competitors and absence of long as well as short term quality policy across all industries. However, it is interesting to note that, there is a strong awareness as well as interest about quality at top management level and quality department heads. Moreover, the industries claim to practice a quality-first motto, no matter how attractive the price and delivery terms are.

This study has also made an effort to assess whether there exist any department working on quality control system and how quality control system is organized in their respective industries. Accordingly, the responses indicated that more than three forth of the industries (88\%) have established a department working on quality control system and similarly $68 \%$ of the industries have noted that the quality control system were organized by department, $27 \%$ of the industries were organized across different departments and $5 \%$ of the industries were organized at expert level (Figure 5 and Figure 6). This revealed that Ethiopian industries are well aware and have shown interest about quality issues at top management level and quality department heads no matter how attractive the prices are. It is promising to mention that, $100 \%$ of the industries in Ethiopia agreed on the importance of quality control tools as being the tools are very important to their organizations' productivity and quality improvement.

Furthermore, this study was also interested to know that who designed the quality control system implemented in your organization. Majority of the respondents (35.9\%) have indicated that the quality control system was designed by expatriates (Figure 12). In connection to this, about $75 \%$ of the respondents have noted that there is no research department working on productivity, quality and profitability of their organization (Figure 13). This is a common problem among the Ethiopian industries; an industry that was producing something ten years ago produces the same product with no improvement in quality, material or production system which proves the lack of strong research and development department. In general, the industries in Ethiopia be deficient in vigor and found to be stagnant hence less exposed to a highly competitive market and don't adopting the latest management techniques in order to gain knowledge about systems to improve quality and operational performance. A research work of Nigeria Breweries Plc, Enugu, south east of Nigeria was carried out to examine the problems of quality control in manufacturing firms, the various techniques of quality control used and to assess the effectiveness and efficiency of their applications [31]. This study also set to find out what manufacturing firms seek to achieve through quality control practice. From the results of this research work, it has been revealed that quality control techniques are crucial tools for a successful business since the application of quality control techniques can help to ensure the production of high quality products to consumer satisfaction which in turn result to a successful business [31]. This study coincides with the empirical study that examined quality awareness and developments of product quality conducted in Ethiopia that revealed that, $72.8 \%$ of the surveyed industries have no incentive programs related to quality improvement, $62.8 \%$ have no established PDSA cycle, $57.1 \%$ have no information about the product quality of their competitors, while, 50\% don't have long as well as short term quality policy [30]. 
Manufacturing industries have also been asked to determine the level of awareness on how quality control methods used to practice with regard to their procedures. Of the respondents about $95.5 \%$ have noted that quality control methods are practiced at all levels starting from the raw materials and about $4.5 \%$ of the industries have experience to practice on finished products (Figure 8). This study has also covered several questions with regard to quality control professionals to determine whether they are aware and practiced quality control tools to meet customer satisfaction. In line with this, of the industries $84.5 \%$ have reported that short term training opportunity is given to quality control professionals, $4.5 \%$ both short term and long term is given and $11.5 \%$ no training opportunity is given (Figure 10). Similarly, respondents were asked where quality control training is given to their employees. Majority of the respondents (43\%) have indicated that quality control training would be given in both within country and organization (Figure 11).

A quality control tool may be described as a method which has a clear role and defined application; it is often limited in its focus and can be and usually is used on its own (e.g., fish-bone diagram). For this several questions were asked to the organizations. First was awareness of SPC and second was usage of statistical process control (SPC). This study revealed that majorities of the respondents didn't have experience in using statistical methods as quality control mechanism (Figure 14). In line with this, most of the quality department of the industries did not fully recognize the importance of statistical process control as quality control tools (Figure 15). Respondents were also asked if any training is given concerning SPC. Majority of the respondents (62\%) have indicated that they did not get any training concerning SPC (Figure 16). This is mainly due to lack of awareness on statistical process control as respondents had noted in Figure 18. Quality control professionals were also asked to the extent that quality control system is working in your industry. Accordingly, majority of the respondents (45\%) have indicated that quality control system is working to some extent in their respective industries (Figure 18). In line with this, respondents have mentioned that the challenges for using quality control tools is that lack of motivation and awareness of the management, shortage of man power in the area, and others together would make it difficult to apply quality control tools in their organizations (Figure 19). This finding is consistent with a research work of Nigeria Breweries Plc, Enugu, south east of Nigeria that had been carried out to examine the problems of quality control in manufacturing firms and has indicated that the benefit of quality control and its techniques can only be assured by the effective and efficient application of these techniques. The study in Nigeria has noted that manufacturing firms encounter a lot of problems for applying quality control practice. Among these factor, above all, non-awareness of quality control techniques, inability to understand the need of customers, cost of applying quality control techniques, non-availability of equipment to be used and negative attitude of employees more especially top management in the firm are to be mentioned [31].

Furthermore, this work relies on qualitative methods to collect and compile the empirical evidence. It was based on in-depth interviews with the company executives 
and/or quality control directors and internal company's' documents were scrutinized. This study has also pointed out that poor data management system (measurements poorly recorded during the process of production) was observed in all the sampled manufacturing industries. Information was also not shared between the different organizational structures of a company. This might affect the quality control system of the industries. Hence, there has to be a unit that is responsible for recording the measurements occurred during the process of production. If quality department is established as an independent system with a real power; the department which is responsible for quality can make an irreversible decision with respect to quality of a product. This could improve the quality control system of the industries.

\section{Conclusions and Recommendations}

Most of the quality department of the industries did not fully recognize the importance of statistical process control as quality control tools. Majority of the respondents (62\%) have indicated that they did not get any training concerning SPC. This is mainly due to lack of awareness and motivation of top managements on statistical process control. Quality control professionals were also asked to what extent that quality control system is working in their industry and majority of the respondents (45\%) have indicated that quality control system is working to some extent in their respective industries (Figure 19). This might be due to the fact that lack of motivation and awareness of the management, shortage of man power in the area, and others together would make it difficult to apply quality control tools in their organization (Figure 20). In general, the industries in Ethiopia be deficient in vigor and found to be stagnant hence less exposed to a highly competitive market and don't adopting the latest management techniques in order to gain knowledge about systems to improve quality and operational performance. Hence, we concluded that quality management system has to be established as an independent entity with a real power and hence the quality control department which is responsible for quality can make an irreversible decision with respect to quality of a product. Moreover, the concerned bodies (government and minister of industries) should give attention and work together with universities to ensure that how these statistical process control techniques could be incorporated in a curriculum at higher level in degree and masters program. Furthermore, different trainings which cloud improve quality and efficiency of their respective management system should be given as short and long term to the employees including top and middle managers found in various industries relevant to their process.

\section{References}

[1] Garvin, D.A. (1987) Competing in the Eight Dimensions of Quality. Harvard Business Review, 87, 101-109.

[2] Montgomery, D.C. (2009) Introduction to Statistical Quality Control. 6th Edition, John Wiley \& Sons Inc., Hoboken.

[3] Nnamani, C.N. and Fobasso, S.H. (2013) Statistical Quality Control of Manufactured Products (Case Study of Packaging at Lifespan Pharmaceutical Limited). International 
Journal of Pure and Applied Sciences and Technology, 15, 20-30.

[4] Bisgaard, S. and De Mast, J. (2006) After Six Sigma-What's Next? Quality Progress, 39, 3036.

[5] Teece, D.J. (2007) Explicating Dynamic Capabilities: The Nature and Micro Foundations of (Sustainable) Enterprise Performance. Strategic Management Journal, 28, 1319-1350. http://dx.doi.org/10.1002/smj.640

[6] Upton, D. (1996) Mechanisms for Building and Sustaining Operations Improvement. European Management Journal, 14, 215-228. http://dx.doi.org/10.1016/0263-2373(96)00002-3

[7] Juergensen, T. (2000) Continuous Improvement: Mindsets, Capability, Process, Tools and Results. The Juergensen Consulting Group Inc., Indianapolis.

[8] Bessant, J., Caffyn, S., Gilbert, J., Harding, R. and Webb, S. (1994) Rediscovering Continuous Improvement. Technovation, 14, 17-29.

http://dx.doi.org/10.1016/0166-4972(94)90067-1

[9] Pay, R. (2008) Everybody's Jumping on the Lean Bandwagon, but Many Are Being Taken for a Ride. Industry Week.

[10] Kiernan, M.J. (1996) Get Innovative or Get Dead. Business Quarterly, 61, 51-58.

[11] Wruck, K.H. and Jensen, M.C. (1998) The Two Key Principles behind Effective TQM Program. European Financial Management, 4, 401-423. http://dx.doi.org/10.1111/1468-036X.00073

[12] Voss, C.A. (2005) Paradigms of Manufacturing Strategy Revisited. International Journal of Operations \& Production Management, 25, 1223-1227. http://dx.doi.org/10.1108/01443570510633620

[13] Womack, J. and Jones, D. (1996) Lean Thinking. Simon and Schuster, New York.

[14] Linderman, K., Schroeder, R., Zaheer, S. and Choo, A. (2003) Six Sigma: A Goal-Theoretic Perspective. Journal of Operations Management, 21, 193-203.

http://dx.doi.org/10.1016/S0272-6963(02)00087-6

[15] Klefsjo, B., Wiklund, H. and Edgeman, R. (2001) Six Sigma Seen as a Methodology for Total Quality Management. Measuring Business Excellence, 5, 31-35. http://dx.doi.org/10.1108/13683040110385809

[16] Bhuiyan, N. and Baghel, A. (2005) An Overview of Continuous Improvement: From the Past to the Present. Measurement Decision, 13, 761-771. http://dx.doi.org/10.1108/00251740510597761

[17] Kaplan, R. and Norton, D. (1996) The Balanced Scorecard: Translating Strategy into Action. Harvard Business School Press, Cambridge.

[18] Srinivasu, R., Satyanarayana, R.G. and Rikkula, S.R. (2011) Utility of Quality Control Tools and Statistical Process Control to Improve the Productivity and Quality in an Industry. International Journal of Reviews in Computing, 5, 2076-3328. www.kaizen-institute.com

[19] Oakland, J.S. (2003) Statistical Process Control. 5th Edition, Butterworth-Heinemann, Oxford.

[20] Xie, M. and Goh, T.N. (1999) Statistical Techniques for Quality. The TQM Magazine, 11, 238-242. http://dx.doi.org/10.1108/09544789910272913

[21] Hairulliza, M.J., Hazura, M. and Erna, B.N. (2005) Aplikasi Carta Kawalan Dalam Industri Produk Minuman.

[22] http://www.qualitymag.com/articles/85973-remembering-walter-a-shewhart-s-contribution -to-the-quality-world 
[23] Benneyan, J.C., Lloydr, C. and Plsekp, E. (2003) Statistical Process Control as a Tool for Research and Healthcare Improvement. Quality and Safety in Health Care, 12, 458-464. http://dx.doi.org/10.1136/qhc.12.6.458

[24] Barnes, T. (1996) Kaizen Strategies for Successful Leadership. Pitman Publishing, London.

[25] Grigg Nigel, P. (1998) Statistical Process Control in UK Food Production: An Overview. International Journal of Quality \& Reliability Management, 15, 223-238. http://dx.doi.org/10.1108/02656719810196360

[26] Raghuraman, S., Thiruppathi, K., Praveen Kumar, J. and Indhirajith, B. (2012) Enhancement of Quality of the Processes Using Statistical Tools-A Review. International Journal of Engineering Science \& Advanced Technology, 2, 1008-1017.

[27] Ministry of Finance and Economic Development (2010) Federal Democratic Republic of Ethiopia. Growth and Transformation Plan (2010/11-1014/15), Addis Ababa.

[28] Magar, V.M. and Shinde, V.B. (2014) Application of 7 Quality Control (7 QC) Tools for Continuous Improvement of Manufacturing Processes. International Journal of Engineering Research and General Science, 2, 364-371.

[29] Raghavendra, S.T.V.S., Manideep, B., PremSai, R. and Adi Siva Kishore Reddy, Y. (2013) A Case Study on Total Quality Control Of Manufacturing Of Liners By Applying Spc Technique. International Journal of Engineering Research and Applications, 3, 357-368. www.ijera.com

[30] Kahsay, G., Osanna, P.H. and Durakbasa, N.M. Investigation of Quality Awareness, Developments and Factors Impeding Product Quality Improvement in Ethiopian Medium and Large Scale Manufacturing Industries.

[31] Ijeoma Marire, M., Ekpere Nwankwo, B. and Sydney-Agbor, N. (2014) The Problems of Quality Control in the Manufacturing Sector A Study of Nigeria Breweries Plc, Enugu. IOSR Journal of Business and Management, 16, 96-107.

Submit or recommend next manuscript to SCIRP and we will provide best service for you:

Accepting pre-submission inquiries through Email, Facebook, LinkedIn, Twitter, etc. A wide selection of journals (inclusive of 9 subjects, more than 200 journals)

Providing 24-hour high-quality service

User-friendly online submission system

Fair and swift peer-review system

Efficient typesetting and proofreading procedure

Display of the result of downloads and visits, as well as the number of cited articles

Maximum dissemination of your research work

Submit your manuscript at: http://papersubmission.scirp.org/

Or contact iim@scirp.org 